\title{
Optimized Gen-II FeCrAl cladding production in large quantity for campaign testing
}

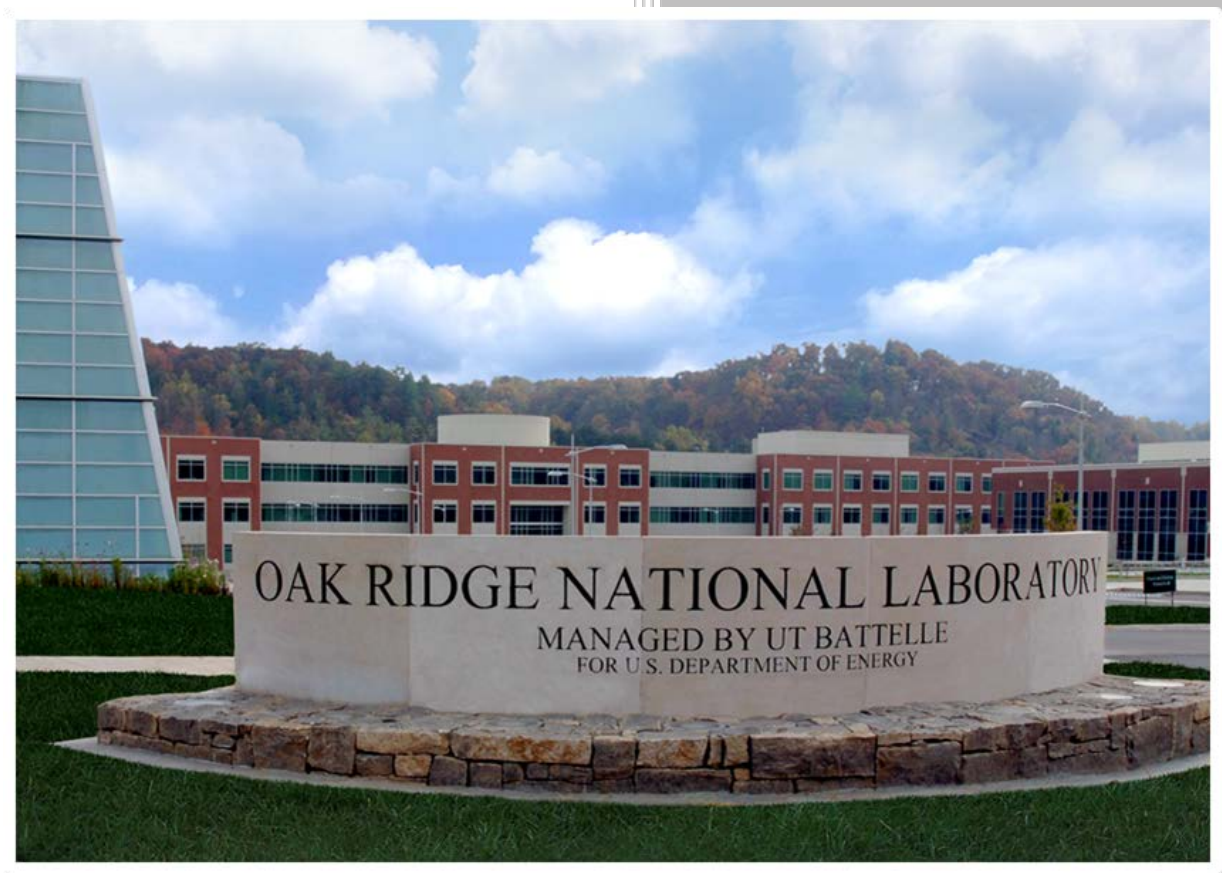

Approved for public release. Distribution is unlimited.

Yukinori Yamamoto

Zhiqian Sun

Bruce A. Pint

Kurt A. Terrani

June $3^{\text {rd }}, 2016$ 


\title{
DOCUMENT AVAILABILITY
}

Reports produced after January 1, 1996, are generally available free via US Department of Energy (DOE) SciTech Connect.

\section{Website http://www.osti.gov/scitech/}

Reports produced before January 1, 1996, may be purchased by members of the public from the following source:

\author{
National Technical Information Service \\ 5285 Port Royal Road \\ Springfield, VA 22161 \\ Telephone 703-605-6000 (1-800-553-6847) \\ TDD 703-487-4639 \\ Fax 703-605-6900 \\ E-mail info@ntis.gov \\ Website http://www.ntis.gov/help/ordermethods.aspx
}

Reports are available to DOE employees, DOE contractors, Energy Technology Data Exchange representatives, and International Nuclear Information System representatives from the following source:

Office of Scientific and Technical Information

PO Box 62

Oak Ridge, TN 37831

Telephone 865-576-8401

Fax 865-576-5728

E-mail reports@osti.gov

Website http://www.osti.gov/contact.html

This report was prepared as an account of work sponsored by an agency of the United States Government. Neither the United States Government nor any agency thereof, nor any of their employees, makes any warranty, express or implied, or assumes any legal liability or responsibility for the accuracy, completeness, or usefulness of any information, apparatus, product, or process disclosed, or represents that its use would not infringe privately owned rights. Reference herein to any specific commercial product, process, or service by trade name, trademark, manufacturer, or otherwise, does not necessarily constitute or imply its endorsement, recommendation, or favoring by the United States Government or any agency thereof. The views and opinions of authors expressed herein do not necessarily state or reflect those of the United States Government or any agency thereof. 
Fuel Cycle Research and Development, Advanced LWR Fuels

\title{
Optimized Gen-II FeCrAl cladding production in large quantity for campaign testing
}

\author{
Yukinori Yamamoto, Zhiqian Sun, Bruce A. Pint, Kurt A. Terrani
}

Date Published: June $3^{\text {rd }}$, 2016

\section{Work Package Title: ATF Cladding Production Work Package \#: FT-16OR02020213 \\ Work Package Manager: Yukinori Yamamoto \\ Milestone \#: M3FT-16OR020202132}

Prepared under the direction of the

U.S. Department of Energy

Office of Nuclear Energy

Fuel Cycle Research and Development

Advanced LWR Fuels

Prepared by

OAK RIDGE NATIONAL LABORATORY

Oak Ridge, TN 37831-6283

managed by

UT-BATTELLE, LLC

for the

US DEPARTMENT OF ENERGY

under contract DE-AC05-00OR22725 



\section{CONTENTS}

Page

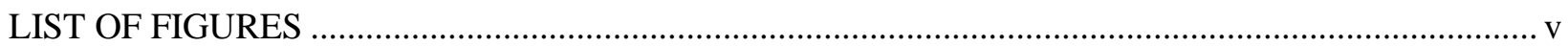

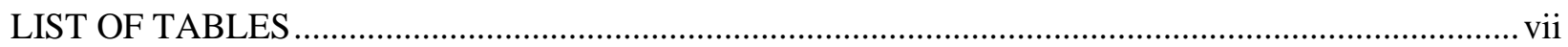

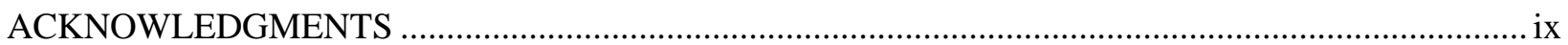

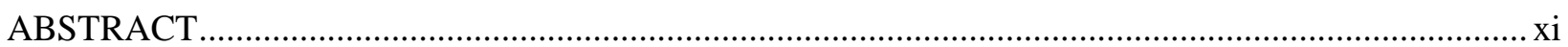

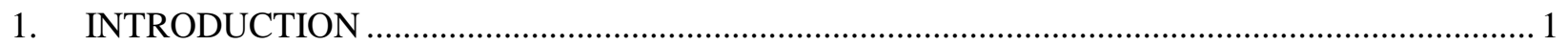

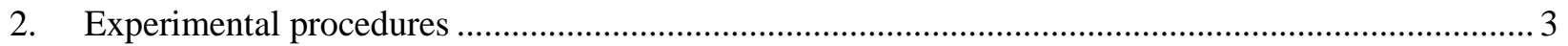

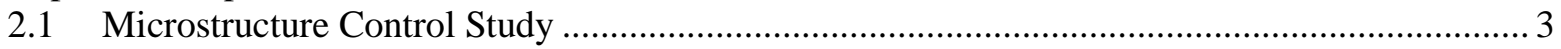

2.2 Tube Production with Commercial Manufacturers............................................................... 3

3. Optimization of Microstructure Control during Tube Drawing.................................................. 6

3.1 Effect of Annealing Temperatures on Warm-rolled C35M3 .................................................. 6

3.2 Microstructure Evolution during Stepwise Rolling of C35M4 (Simulating Tube-

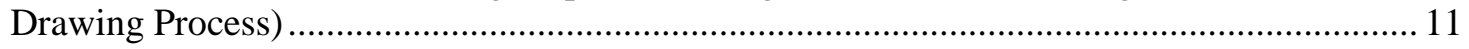

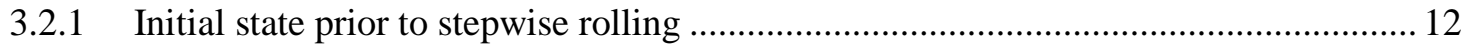

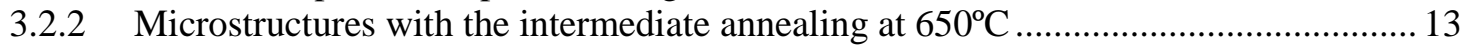

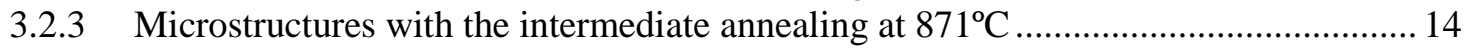

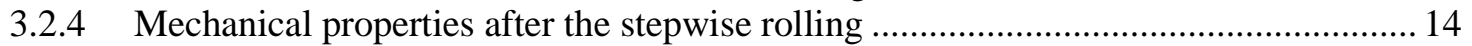

3.3 Microstructural Control of Nb-containing FeCrAl Alloys................................................. 16

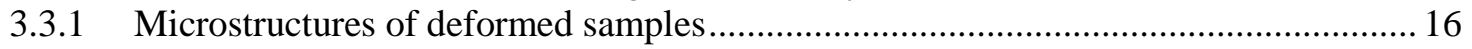

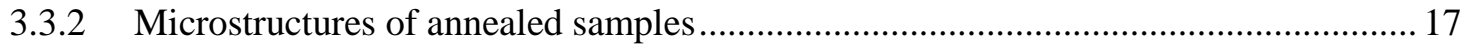

3.3.3 Mechanical properties of deformed and annealed samples......................................... 21

4. ATF FeCrAl tube production via commercial manufacturers ....................................................... 22

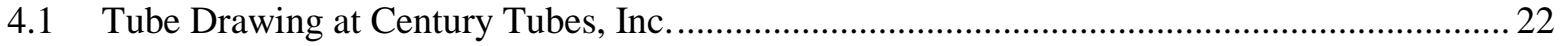

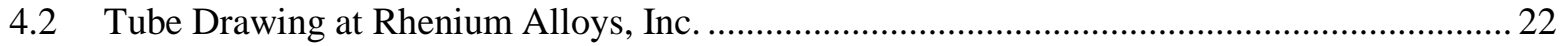

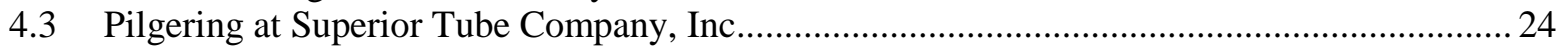

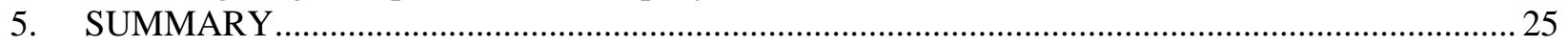

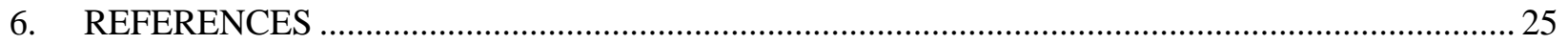





\section{LIST OF FIGURES}

Figure

Figure 1. Commercial thin-wall tube fabrication processes; (a) tube drawing with a mandrel [15], and (b) pilgering [16]. Note that HPTR and VMR stand for "high-precision tube roller" and "vertical mass ring die", respectively

Figure 2. Effects of annealing at $550-750^{\circ} \mathrm{C}$ on the Vickers hardness of C35M3 with initial strains of (a) $10 \%$, (b) $20 \%$, and (c) $40 \%$.

Figure 3. Optical micrographs of the C35M3 samples with the initial thickness reduction of $10 \%$ :

(a) as-rolled; (b) annealed $4 \mathrm{~h}$ at $550^{\circ} \mathrm{C}$; (c) annealed $2 \mathrm{~h}$ at $650^{\circ} \mathrm{C}$; and (d) annealed $1 \mathrm{~h}$ at $750^{\circ} \mathrm{C}$

Figure 4. Optical micrographs of the C35M3 samples with the initial thickness reduction of 20\%:

(a) as-rolled; (b) annealed $4 \mathrm{~h}$ at $550^{\circ} \mathrm{C}$; (c) annealed $2 \mathrm{~h}$ at $700^{\circ} \mathrm{C}$; and (d) annealed $1 \mathrm{~h}$ at $750^{\circ} \mathrm{C}$

Figure 5. Optical micrographs of the C35M3 samples with the initial thickness reduction of 40\%:

(a) as-rolled; (b) annealed $4 \mathrm{~h}$ at $550^{\circ} \mathrm{C}$; (c) annealed $2 \mathrm{~h}$ at $650^{\circ} \mathrm{C}$; and (d) annealed $1 \mathrm{~h}$ at $750^{\circ} \mathrm{C}$

Figure 6. Warm-rolling schedule of $\mathrm{C} 35 \mathrm{M} 3$ at $300^{\circ} \mathrm{C}$ ( $\varepsilon^{\prime}$ : strain per step; $\varepsilon$ : total strain).

Figure 7. Stress vs. strain curves of C35M3 for (a) as-rolled and (b) annealed samples. The corresponding curve of initial C35M3 plate (A0) is included for comparison.

Figure 8. Effects of annealing $\left(650^{\circ} \mathrm{C}-1 \mathrm{~h}\right)$ on (a) tensile properties, (b)Vickers hardness, and (c) plastic uniform strain for rolled C35M3.

Figure 9. Optical micrographs of the stepwise rolled and annealed C35M3; (a) A0, (b) B1, and (c) B3a

Figure 10. Strain per pass (blue) and total strain (red) in the stepwise warm rolling at $400^{\circ} \mathrm{C}$ of C35M4.

Figure 11. Tensile properties of A0 in a temperature range of $24-800^{\circ} \mathrm{C}$ : (a) yield stress (filled symbols)/ultimate tensile stress (open symbols) and (b) uniform strain (filled symbols) and failure strain (open symbols).

Figure 12. Inverse Pole Figure maps and (001), (110), and (111) pole figures of A1' (a \& d), A7' (b \& e), and A16' (c \& f). The EBSD step sizes were 1.0, 0.8, and 0.8 $\mu \mathrm{m}$ for A1', A7', and A16', respectively. Note that (a), (b), and (c) have the same size scale.

Figure 13. Backscattered electron image of subgrains in A16'.

Figure 14. IPF maps and (001), (110), and (111) pole figures of B1' (a \& d), B7' (b \& e), and B16' (c \& f). The EBSD step sizes were 1.0, 0.8, and 0.8 $\mu \mathrm{m}$ for A1', A7', and A16', respectively. Note that (a), (b), and (c) have the same size scale.

Figure 15. Vickers hardness of as-rolled (filled markers) and annealed (unfilled markers) C35M4 samples after the $1^{\text {st }}, 4^{\text {th }}, 7^{\text {th }}$, and $16^{\text {th }}$ passes (blue: $650^{\circ} \mathrm{C}-1 \mathrm{~h}$; red: $871^{\circ} \mathrm{C}-30 \mathrm{~min}$ ).

Figure 16. (a) Typical optical micrographs of as-rolled specimens showing band-like structures along the rolling direction; (b) IPF map of the as-rolled C36N sample; and (c) backscattered electron image of the as-rolled C36N2 sample showing Laves phase particles (with bright contrast).

Figure 17 . Initiation of recrystallization at $650-800^{\circ} \mathrm{C}$ observed by optical microscopy for C36N $(1 \mathrm{Nb}), \mathrm{C} 36 \mathrm{~N} 3(0.7 \mathrm{Nb})$, and C36M2 (0Nb).

Figure 18. IPF maps of C36N samples after annealing at $700^{\circ} \mathrm{C}$ for (a) $1 \mathrm{~h}$ and (b) $96 \mathrm{~h}$. Grain boundaries with misorientation greater than $15^{\circ}$ would be marked by black lines. Backscattered electron images shows Laves phase particles (bright contrast) and subgrains in $\mathrm{C} 36 \mathrm{~N}$ samples annealed at $700^{\circ} \mathrm{C}$ for (c) $8 \mathrm{~h}$ and (d) $96 \mathrm{~h}$. 
Figure 19. IPF maps of C36N samples after annealed for $24 \mathrm{~h}$ at (a) $800^{\circ} \mathrm{C}$ and (b) $900^{\circ} \mathrm{C}$. Grain boundaries with the misorientation greater than $15^{\circ}$ are marked by black lines. The (001), (110), and (111) pole figures of (b) are shown in (c).

Figure 20. Backscattered electron images of C36N samples annealed at $900^{\circ} \mathrm{C}$ for (a) $1 \mathrm{~h}$ and (b) $24 \mathrm{~h}$.

Figure 21. (a) Effect of annealing at $600-900{ }^{\circ} \mathrm{C}$ on the Vickers hardness of C36N samples; (b) Comparison of the annealing effect at $700{ }^{\circ} \mathrm{C}$ on the Vickers hardness of C36N, C36N2, C36N3, and C36M2 samples; (c) Tensile properties of as-rolled and annealed C36N samples.

Figure 22. As-received C06M2 thin wall tube produced by CTI; a picture of whole tube (a), and optical micrographs of cross section (b) and longitudinal section (c).

Figure 23. Optical micrograph montage of cross-sectional view of as-received C06M2 tube, together with a list of wall thickness at various locations 


\section{LIST OF TABLES}

Table

Table 1. Analyzed compositions of alloys studied. ............................................................................. 3

Table 2. List of commercial manufacturers for thin-wall FeCrAl tube production .................................... 4

Table 3. Manufacturer list and plan status for tube production .............................................................. 4

Table 4. Analyzed compositions of the alloys for tube production ........................................................... 5 
This page intentionally left blank 


\section{ACKNOWLEDGMENTS}

The authors are grateful to Kory Linton of Oak Ridge National Laboratory (ORNL) for his helpful discussions and management, and Tom Geer, Dave Harper, Greg Cox, Dustin Heidel, and Zhiqian Sun of ORNL, Jim Patterson of Sophisticated Alloys, Inc., Tim Falso of Grover Gundrilling, LLC., Kelli Major of Century Tubes, Inc., Todd Leonhardt, Don Mitchel, Joe Johnson, and Randy Weld of Rhenium Alloys, Inc., and Kevin Heaphy and Bill Keohane at Superior Tube Company, Inc. for their technical supports. The time spent by Sam Briggs of ORNL in reviewing this report is also greatly appreciated.

This research was funded by the U.S. Department of Energy's Office of Nuclear Energy, Advanced Fuel Campaign of the Fuel Cycle R\&D program. 
This page intentionally left blank 


\section{ABSTRACT}

There are two major objectives in this report; (1) to optimize microstructure control of ATF FeCrAl alloys during tube drawing processes, and (2) to provide an update on the progress of ATF FeCrAl tube production via commercial manufacturers.

Experimental efforts have been made to optimize the process parameters balancing the tube fabricability, especially for tube drawing processes, and microstructure control of the final tube products. Lab-scale sheet materials of Gen II FeCrAl alloys (Mo-containing and Nb-containing FeCrAl alloys) were used in the study, combined with a stepwise warm-rolling process and intermediate annealing, aiming to simulate the tube drawing process in a commercial tube manufacturer. The intermediate annealing at $650^{\circ} \mathrm{C}$ for $1 \mathrm{~h}$ was suggested for the tube-drawing process of Mo-containing $\mathrm{FeCrAl}$ alloys because it successfully softened the material by recovering the work hardening introduced through the rolling step, without inducing grain coarsening due to recrystallization. The final tube product is expected to have stabilized deformed microstructure providing the improved tensile properties with sufficient ductility. Optimization efforts on $\mathrm{Nb}$-containing $\mathrm{FeCrAl}$ alloys focused on the effect of alloying additions and annealing conditions on the stability of deformed microstructure. Relationships between the second-phase precipitates $\left(\mathrm{Fe}_{2} \mathrm{Nb}\right.$-Laves phase) and microstructure stability are discussed.

FeCrAl tube production through commercial tube manufacturers is currently in progress. Three different manufacturers, Century Tubes, Inc. (CTI), Rhenium Alloys, Inc. (RAI), and Superior Tube Company, Inc. (STC), are providing capabilities for cold-drawing, warm-drawing, and HPTR cold-pilgering, respectively. The first two companies are currently working on large quantity tube production (expected $250 \mathrm{ft}$ length) of Gen I model FeCrAl alloy (B136Y3, at CTI) and Gen II (C35M4, at RAI), with the process parameters obtained from the experimental efforts. The expected delivery dates are at the end of July, 2016, and the middle of June, 2016, respectively. Tube production at STC would be the first attempt to apply cold-pilgering to the $\mathrm{FeCrAl}$ alloys. Communication has been initiated, and the materials have been machined for the cold-pilgering process. 


\section{INTRODUCTION}

The development of nuclear-grade enhanced accident tolerant fuel (ATF) cladding alloys targets a new, metal-base structural material for nuclear fuel cladding in Light Water Reactors (LWR). These materials will replace the current zirconium-based alloy fuel cladding and should exhibit greatly improved accident tolerance, including good mechanical properties across a wide temperature range in addition to excellent oxidation and radiation resistance under normal and transient operating conditions. FeCrAl alloys were selected based on their excellent oxidation resistance in high temperature steam environments up to $1475^{\circ} \mathrm{C}$ (provided by the sufficient amounts of $\mathrm{Cr}$ and $\mathrm{Al}$ additions), compared to the industry standard zirconium alloys which do not have such high temperature tolerances [1,2,3,4]. This is the key for enhancing safety margins under severe accident conditions by limiting heat and hydrogen production, which occur when the fuel cladding reacts with steam during a severe accident [5]. With superior high temperature strength compared to zirconium alloys, utilization of this class of alloys is expected to enhance burst margins during design basis accident scenarios and potentially for conditions extending beyond those limits.

Development efforts for ATF FeCrAl alloys were initiated in FY2013 under the Fuel Cycle Research and Development (FCRD) program, which consisted of two distinct phases, each evaluating a different alloy generation; in Phase 1: Gen I model FeCrAl alloys, and in Phase 2: Gen II modified FeCrAl alloys [6]. In Phase 1, the Gen I model FeCrAl alloys, consisting of quaternary Fe-Cr-Al-Y alloys, were used for property screening as a function of $\mathrm{Cr}$ and $\mathrm{Al}$ content. A base alloy composition of Fe-13Cr-4.5Al-Y was down-selected based on experimental findings demonstrating good balance between mechanical properties, oxidation resistance, irradiation resistance, weldability, and so on $[7,8,9,10]$. In Phase 2 , minor alloying additions were applied with guidance from computational thermodynamics for improved strength together with sufficient oxidation resistance at elevated temperatures, without sacrificing acceptable fabricability to support FeCrAl thin-wall tube product with commercial manufacturers. The comprehensive summary of the Gen II modified FeCrAl alloy development and property evaluation can be found in the reports previously submitted $[11,12,13]$.

In LWRs, a seamless tube product is required for the fuel cladding which typically has a length of $\sim 4 \mathrm{~m}$ with an outer diameter of $\sim 10 \mathrm{~mm}$. In the case of FeCrAl alloys, a wall-thickness of less than $0.4 \mathrm{~mm}$ is also suggested for reducing potential neutronic impact compared to current zirconium alloy cladding [14]. The FeCrAl cladding should also be structurally sound with sufficient mechanical properties at both service temperature and accident conditions. These requirements impose considerable technical challenges for tube fabrication processes of FeCrAl alloys. Research has been performed to achieve a balance between high-temperature performance and tube fabricability in newly developed FeCrAl alloys. BCC-Fe materials with $\mathrm{Cr}$ and $\mathrm{Al}$ additions typically suffer from poor ductility because of relatively high ductile-brittle transition temperature [15]. Microstructural stability of the refined grain or subgrain structure at high temperature is critical to maintain both the fabricability of the alloys during tube production processes and the mechanical properties of the final tube products.

There are two different approaches to fabricate a seamless thin-wall tube commercially: tube-drawing and pilgering - both shown in Figure 1 [16,17]. The tube-drawing process is widely applied for making thin-wall tubes used in various industries: architectures, boilers, petrochemical and chemical plants, nuclear and fossil energy plants, aerospace, vehicles, medical equipment, appliances, etc. A die and mandrel are required to reduce and control the outer diameter (OD) and the inner diameter (ID) as shown in Figure 1a. Tube drawing is occasionally conducted under warm conditions (up to $\sim 300^{\circ} \mathrm{C}$ ), depending on the die and mandrel materials, to make the fabrication process easier. 
Pilgering was developed for manufacturing tubing with ultrathin walls for nuclear fuel cladding in the 1950's [18]. The high-precision tube roller (HPTR) method provides a fast, economical way to achieve extreme reductions in diameter and wall thickness. The vertical mass ring (VMR) die method uses a couple of rotating dies with varying radius for smooth tube deformation to achieve a more than $90 \%$ cross-sectional reduction in a single working cycle. Both pilgering approaches can be categorized as compressive production routes similar to a conventional rolling process, and are suitable for applying larger deformation than tube-drawing processes, although they typically require a large capital investment and are not feasible for the production of small quantities of tubing.

(a) Tube drawing

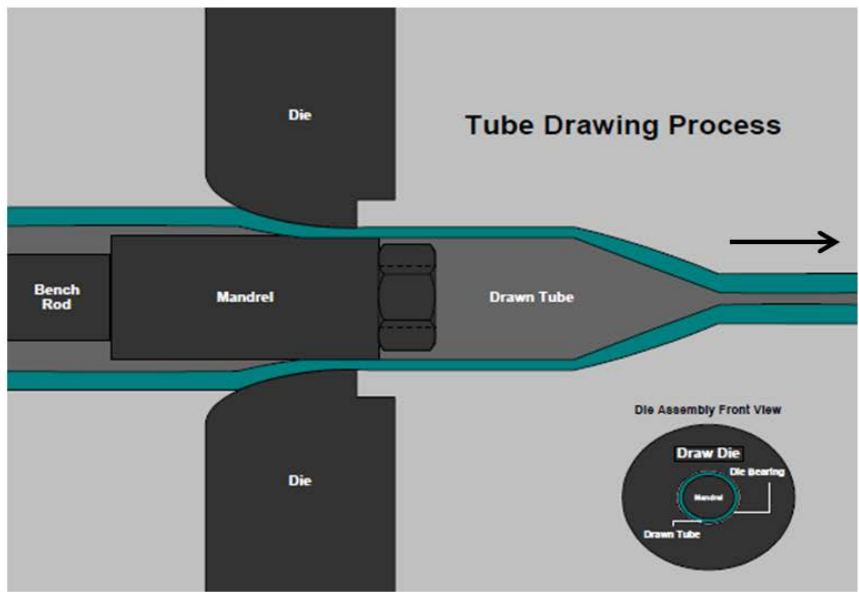

(b) Pilgering

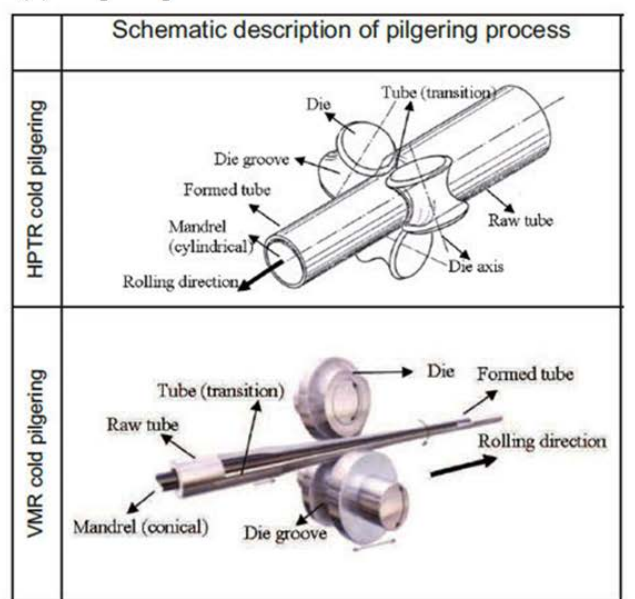

Figure 1. Commercial thin-wall tube fabrication processes; (a) tube drawing with a mandrel [16], and (b) pilgering [17]. Note that HPTR and VMR stand for "high-precision tube roller" and "vertical mass ring die”, respectively.

There are two major objectives in this report; (1) to optimize process parameters of the tube drawing process for a large-quantity production of ATF FeCrAl thin-wall tubes by commercial manufacturers, and (2) to report on the progress of ATF FeCrAl tube production via commercial manufacturers. The first part of the report focuses on microstructure evolution and hardness evaluation of selected FeCrAl alloys during simulated tube fabrication processes with various process parameters. In order to optimize fabricability and mechanical properties of the FeCrAl alloys in the final tube products the required processing window had to be defined. The study was conducted using lab-scale sheet materials with warm-rolling processes to simulate the applied deformation and microstructure evolution during the warm-drawing and annealing process to enable direct transfer of these results to large-quantity tube production. The second objective is to report on tube production progress with three commercial tube manufacturers, Century Tubes, Inc. (CTI), Rhenium Alloys, Inc. (RAI), and Superior Tube Company, Inc. (STC), with capabilities of cold-drawing, warm-drawing, and HPTR cold-pilgering, respectively. The first two companies have conducted the FeCrAl alloy tube production since FY2014 under subcontract with the current FCRD projects, and they are currently working on large-quantity tube production (expected $250 \mathrm{ft}$. length) of Gen I (CTI) and Gen II (RAI). The most-recent progress on tube production is described. Tube production at STC will be challenging since it is the first attempt to apply cold-pilgering to the developed ATF FeCrAl alloys under the current project. The materials provided to STC were identical to those processed at CTI (Gen II FeCrAl alloys) to enable direct comparison between tubedrawing and pilgering. These details are described in this report. 


\section{EXPERIMENTAL PROCEDURES}

\subsection{Microstructure Control Study}

Two different series of Gen II ATF FeCrAl alloys were used in the microstructure control study; Mocontaining alloys and Nb-containing alloys. The nominal alloy compositions were mostly based on Fe13Cr-(5.2 or 6)Al-0.2Si-Y, in wt.\%, with the additions of $2 \mathrm{Mo}$ or $(0.7-2) \mathrm{Nb}$. The effect(s) of varying the $\mathrm{Cr}$ content was also examined in the $\mathrm{Nb}$ containing alloys. Analyzed compositions of the alloys are summarized in Table 1.

Table 1. Analyzed compositions of alloys studied.

\begin{tabular}{|l|l|l|l|l|l|l|l|l|l|l|l|}
\hline \multirow{2}{*}{ ID } & \multicolumn{10}{|l}{ Composition, wt.\% } \\
\cline { 2 - 13 } & $\mathbf{F e}$ & $\mathbf{C r}$ & $\mathbf{A l}$ & $\mathbf{Y}$ & $\mathbf{M o}$ & $\mathbf{S i}$ & $\mathbf{N b}$ & $\mathrm{C}$ & $\mathrm{S}$ & $\mathrm{O}$ & $\mathrm{N}$ \\
\hline C35M3 & $\mathbf{7 9 . 4 3}$ & $\mathbf{1 3 . 0 6}$ & $\mathbf{5 . 3 1}$ & $\mathbf{0 . 0 5 3}$ & $\mathbf{2 . 0 0}$ & $\mathbf{0 . 1 3}$ & $<\mathbf{0 . 0 1}$ & 0.001 & $<0.0003$ & 0.0012 & 0.0003 \\
\hline C35M4-1 & $\mathbf{7 9 . 6 3}$ & $\mathbf{1 2 . 9 1}$ & $\mathbf{5 . 2 2}$ & $\mathbf{0 . 0 6 0}$ & $\mathbf{1 . 9 8}$ & $\mathbf{0 . 2 0}$ & - & $<0.01$ & 0.001 & - & - \\
\hline C35M4-2 & $\mathbf{7 9 . 5 6}$ & $\mathbf{1 2 . 8 9}$ & $\mathbf{5 . 2 5}$ & $\mathbf{0 . 0 4 0}$ & $\mathbf{2 . 0 6}$ & $\mathbf{0 . 2 0}$ & - & $<0.01$ & 0.001 & - & - \\
\hline C36M2 & $\mathbf{7 8 . 4 0}$ & $\mathbf{1 3 . 0 0}$ & $\mathbf{6 . 2 9}$ & $\mathbf{0 . 0 5 9}$ & $\mathbf{1 . 9 9}$ & $\mathbf{0 . 2 0}$ & $<\mathbf{0 . 0 1}$ & 0.001 & $<0.0003$ & 0.001 & 0.0004 \\
\hline C16N & $\mathbf{8 1 . 7 2}$ & $\mathbf{1 1 . 0 8}$ & $\mathbf{5 . 9 5}$ & $\mathbf{0 . 0 4 5}$ & $<\mathbf{0 . 0 1}$ & $\mathbf{0 . 1 9}$ & $\mathbf{0 . 9 9}$ & 0.005 & 0.0008 & 0.0013 & 0.0003 \\
\hline C26N & $\mathbf{8 0 . 7 5}$ & $\mathbf{1 2 . 1 0}$ & $\mathbf{5 . 9 6}$ & $\mathbf{0 . 0 2 7}$ & $<\mathbf{0 . 0 1}$ & $\mathbf{0 . 1 7}$ & $\mathbf{0 . 9 8}$ & 0.005 & 0.0009 & 0.0013 & 0.0004 \\
\hline C36N & $\mathbf{7 9 . 7 4}$ & $\mathbf{1 3 . 1 1}$ & $\mathbf{5 . 9 4}$ & $\mathbf{0 . 0 5 8}$ & $<\mathbf{0 . 0 1}$ & $\mathbf{0 . 1 5}$ & $\mathbf{0 . 9 8}$ & 0.004 & 0.001 & 0.0015 & 0.0003 \\
\hline C36N2 & $\mathbf{7 8 . 8 2}$ & $\mathbf{1 3 . 0 0}$ & $\mathbf{5 . 9 4}$ & $\mathbf{0 . 0 5 5}$ & $<\mathbf{0 . 0 1}$ & $\mathbf{0 . 2 0}$ & $\mathbf{1 . 9 7}$ & 0.004 & 0.001 & 0.0021 & 0.0004 \\
\hline C36N3 & $\mathbf{8 0 . 1 9}$ & $\mathbf{1 2 . 7 5}$ & $\mathbf{6 . 0 8}$ & $\mathbf{0 . 0 4 0}$ & $<\mathbf{0 . 0 1}$ & $\mathbf{0 . 1 9}$ & $\mathbf{0 . 6 6}$ & 0.003 & 0.0008 & 0.0009 & 0.0007 \\
\hline
\end{tabular}

The Mo-containing alloy ingots were vacuum induction melted by Sophisticated Alloys, Inc. (SAI), Butler, PA. SAI has vacuum induction melt furnaces with capacities up to $500 \mathrm{lbs}$. Two heats of Mocontaining alloys, C35M3 and C35M4, were used in this study. There were two different heats of "C35M4” prepared for the large-quantity FeCrAl tube manufacturing study (Table 1). Heat "C35M4-2" was used in the microstructure control study. C36M2 (Fe-13Cr-6Al-2Mo) was prepared as a reference material for the microstructural stability study. All alloys were homogenized at $1200^{\circ} \mathrm{C}$ for up to $4 \mathrm{~h}$ in argon cover gas, followed by rapid cooling (air cooling + water quenching) to room temperature. The ingots were extruded at $800^{\circ} \mathrm{C}$ at ORNL (C35M3 and C36M2) or $1050^{\circ} \mathrm{C}$ at SAI (C35M4-1 and -2), followed by straightening and centerless grinding to make bar samples with $23-25 \mathrm{~mm}$ diameters. The ground bars were then annealed at $800^{\circ} \mathrm{C}$ for more than $30 \mathrm{~min}$ to create an equiaxed grain structure (80$100 \mu \mathrm{m})$. These bar samples were used as starting materials or master bars for both the microstructure control study and tube manufacturing, respectively.

$\mathrm{Nb}$-containing FeCrAl alloys were prepared by arc-melting and drop-casting. The lab-scale heats with 13 $\mathrm{mm}$ x $25 \mathrm{~mm}$ x $125 \mathrm{~mm}$ dimensions were homogenized at $1200^{\circ} \mathrm{C}$ for up to $2 \mathrm{~h}$ in Ar cover gas, followed by hot-forging, rolling, and annealing at the same temperature to prepare $2.5 \mathrm{~mm}$ thick plates with an equiaxed grain structure $(\sim 100 \mu \mathrm{m})$. These plate samples were used as starting materials for both microstructure control studies.

\subsection{Tube Production with Commercial Manufacturers}

Table 2 shows the processes/products and the commercial manufacturers utilized to conduct the ATF $\mathrm{FeCrAl}$ tube-drawing production including alloy casting, master bar/tube production through extrusion, 
gun drilling, and tube drawing. Table 3 lists the alloys provided to the manufacturers while Table 4 summarizes the analyzed alloy compositions that were used for the tube production efforts. The cast ingots are provided by SAI. The ingots are homogenized and hot extruded to make bar (or tube) shapes and to control the initial microstructure for the subsequent drawing process. The extrusion process with trial heats was conducted at ORNL (for B126Y, C06M2, and C36M3). SAI also performed the extrusion process (for B136Y3 and C35M4). The extruded bars require a gun-drilling process to make the master tubes to be drawn. This was conducted by Century Tubes, Inc. (San Diego, CA) or Rhenium Alloys, Inc. (North Ridgeville, $\mathrm{OH}$ ) for trial heat tube fabrication. For large-quantity production, Grover Gundrilling, LLC (Oxford, ME) performed the gun-drilling task. The tube drawing process is being conducted by CTI and RAI working with LANL/ORNL and ORNL, respectively. In a parallel tube-drawing effort, ORNL is currently working with Superior Tube Company, Inc. (Collegeville, PA) to apply HPTR cold-pilgering for alloys C06M2 and C36M3.

Table 2. List of commercial manufacturers for thin-wall FeCrAl tube production

\begin{tabular}{|c|c|c|}
\hline Process/product & Manufacturer & Remarks \\
\hline $\begin{array}{l}\text { Cast ingots } \\
\text { (>20 lbs.) }\end{array}$ & $\begin{array}{c}\text { Sophisticated Alloys, Inc. } \\
\text { (Butler, PA) }\end{array}$ & Vacuum induction melt, up to 500 lbs. \\
\hline \multirow[b]{2}{*}{ Hot extrusion } & ORNL & For trial heats, 1250 ton press \\
\hline & $\begin{array}{l}\text { Sophisticated Alloys, Inc. } \\
\text { (Butler, PA) }\end{array}$ & For large quantity production \\
\hline \multirow{2}{*}{ Gun drilling } & $\begin{array}{l}\text { Rhenium Alloys, Inc. } \\
\text { (North Ridgeville, OH) }\end{array}$ & For trial heats \\
\hline & $\begin{array}{c}\text { Grover Gundrilling, LCC } \\
\text { (Oxford, ME) }\end{array}$ & For large quantity production \\
\hline \multirow{2}{*}{ Tube drawing } & $\begin{array}{c}\text { Century Tubes, Inc. } \\
\text { (San Diego, CA) }\end{array}$ & Cold drawing, work with LANL/ORNL \\
\hline & $\begin{array}{c}\text { Rhenium Alloys, Inc. } \\
\text { (North Ridgeville, OH) }\end{array}$ & Warm drawing, work with ORNL \\
\hline Pilgering & $\begin{array}{l}\text { Superior Tube Company, Inc. } \\
\text { (Collegeville, PA) }\end{array}$ & Cold pilgering, work ORNL \\
\hline
\end{tabular}

Table 3. Manufacturer list and plan status for tube production

\begin{tabular}{|l|l|l|}
\hline Manufacturer & Alloys & Remarks \\
\hline Century Tubes & B126Y, B136Y2*, C06M2, C36M3 & $\begin{array}{l}\text { B126Y and C06M2 were delivered } \\
\text { through LANL; B136Y2 and C36M3 } \\
\text { are in progress. }\end{array}$ \\
\hline Rhenium Alloys & C35M4* & In progress \\
\hline Superior Tube & C06M2, C36M3 & In progress \\
\hline
\end{tabular}

*aim to produce total $250 \mathrm{ft}$ length 
Table 4. Analyzed compositions of the alloys for tube production

\begin{tabular}{|l|l|l|l|l|l|l|l|l|l|l|l|}
\hline \multirow{2}{*}{ ID } & \multicolumn{9}{|l|}{ Composition, wt.\% } \\
\cline { 2 - 13 } & $\mathbf{F e}$ & $\mathbf{C r}$ & $\mathbf{A l}$ & $\mathbf{Y}$ & $\mathbf{M o}$ & $\mathbf{S i}$ & $\mathbf{N b}$ & C & S & O & N \\
\hline B126Y & $\mathbf{8 1 . 9 9}$ & $\mathbf{1 1 . 9 9}$ & $\mathbf{5 . 9 8}$ & $\mathbf{0 . 0 2 0}$ & - & - & - & 0.003 & 0.0004 & 0.0045 & 0.0003 \\
\hline B136Y3-1 & $\mathbf{8 0 . 8 1}$ & $\mathbf{1 2 . 9 7}$ & $\mathbf{6 . 1 9}$ & $\mathbf{0 . 0 3 0}$ & - & - & - & $<0.01$ & 0.001 & - & - \\
\hline B136Y3-2 & $\mathbf{8 0 . 7 2}$ & $\mathbf{1 3 . 0 1}$ & $\mathbf{6 . 2 4}$ & $\mathbf{0 . 0 3 0}$ & - & - & - & $<0.01$ & 0.001 & - & - \\
\hline C06M2 & $\mathbf{8 1 . 8 4}$ & $\mathbf{9 . 8 8}$ & $\mathbf{6 . 0 3}$ & $\mathbf{0 . 0 5 0}$ & $\mathbf{1 . 9 7}$ & $\mathbf{0 . 2 1}$ & $<\mathbf{0 . 0 1}$ & 0.003 & $<0.01$ & $<0.01$ & $<0.0005$ \\
\hline C35M4-1 & $\mathbf{7 9 . 6 3}$ & $\mathbf{1 2 . 9 1}$ & $\mathbf{5 . 2 2}$ & $\mathbf{0 . 0 6 0}$ & $\mathbf{1 . 9 8}$ & $\mathbf{0 . 2 0}$ & - & $<0.01$ & 0.001 & - & - \\
\hline C35M4-2 & $\mathbf{7 9 . 5 6}$ & $\mathbf{1 2 . 8 9}$ & $\mathbf{5 . 2 5}$ & $\mathbf{0 . 0 4 0}$ & $\mathbf{2 . 0 6}$ & $\mathbf{0 . 2 0}$ & - & $<0.01$ & 0.001 & - & - \\
\hline C36M3 & $\mathbf{7 8 . 8}$ & $\mathbf{1 2 . 9 8}$ & $\mathbf{6}$ & $\mathbf{0 . 0 4 0}$ & $\mathbf{1 . 9 8}$ & $\mathbf{0 . 1 8}$ & $<\mathbf{0 . 0 1}$ & 0.003 & $<0.0003$ & 0.0016 & 0.0002 \\
\hline
\end{tabular}




\section{OPTIMIZATION OF MICROSTRUCTURE CONTROL DURING TUBE DRAWING}

\subsection{Effect of Annealing Temperatures on Warm-rolled C35M3}

The effects of annealing on microstructures and mechanical properties of deformed C35M3 (Gen II, Fe13Cr-5.2Al-2Mo base) with 10\%, 20\% and 40\% initial strain were investigated. The results indicated the need for intermediate annealing at $650^{\circ} \mathrm{C}$ for $1 \mathrm{~h}$ after each tube-drawing step in order to (1) eliminate potential premature failure during the drawing process, and (2) prevent unnecessary grain coarsening. A stepwise warm rolling process on a C35M3 sheet specimen at $300^{\circ} \mathrm{C}$ with intermediate annealing at $650^{\circ} \mathrm{C} / 1 \mathrm{~h}$, simulating the actual tube-drawing process, verified the improved fabricability of C35M3 with annealing.

A hot-rolled and annealed C35M3 plate with an equiaxed grain structure ( $~ 80$ um grains) was prepared as a starting material for the study. The initial Vickers hardness value was $206 \pm 2$. Three initial thickness reductions $\left(10 \%, 20 \%\right.$, and $40 \%$ ) were made via warm-rolling at $300^{\circ} \mathrm{C}$ with $10 \%$ thickness reduction per pass. The Vickers hardnesses of as-rolled C35M3 plates were $263 \pm 4$ (for 10\%), $297 \pm 10$ (for 20\%), and $322 \pm 5$ (for 40\%). Figure 2 shows the annealing effects on the Vickers hardness of C35M3 in the temperature range of $550-750^{\circ} \mathrm{C}$. Overall, the hardness decreased with longer annealing time mainly due to a recovery process (i.e. annihilation of dislocations and point defects) of the deformed materials. Lower hardnesses were achieved with higher annealing temperatures at a given annealing time and initial strain. At $550^{\circ}$ and $650^{\circ} \mathrm{C}$, the hardness values increased proportional to initial strain at a given annealing time. However, this was not the case at $750^{\circ} \mathrm{C}$. As shown in Figure 2, the C35M3 alloy with $40 \%$ initial strain annealed for $1 \mathrm{~h}$ at $750^{\circ} \mathrm{C}$ had the lowest hardness value (203 \pm 4$)$.

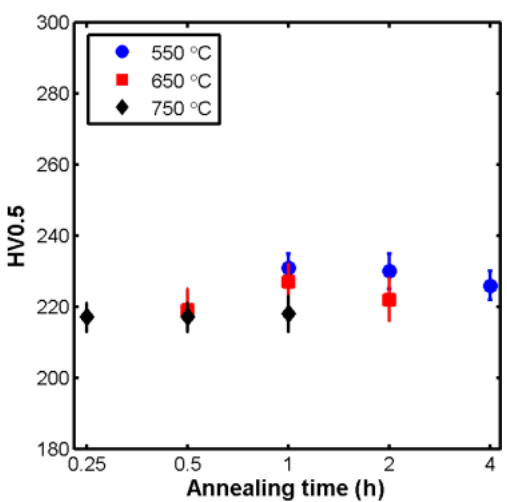

(a)

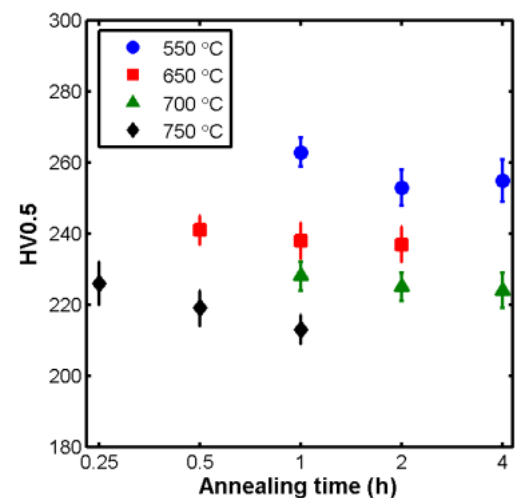

(b)

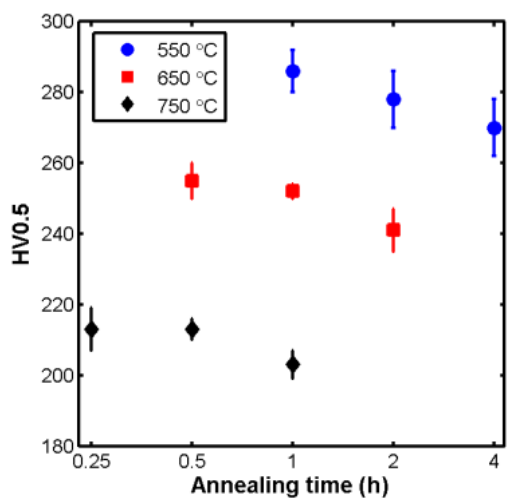

(c)

Figure 2. Effects of annealing at $550-750^{\circ} \mathrm{C}$ on the Vickers hardness of C35M3 with initial strains of (a) $10 \%$, (b) $20 \%$, and (c) $40 \%$.

Representative optical micrographs of the as-rolled and annealed C35M3 are displayed in Figure 3, Figure 4, and Figure 5. No obvious microstructural changes were observed in C35M3 with 10\% initial strain after annealing at the designated conditions (Figure 3). However, with 20\% initial strain, a grain spheroidization and non-uniform grain growth was observed after annealing at $750{ }^{\circ} \mathrm{C}$, as shown in Figure 4. For even larger initial strain (40\%), a full recrystallization was observed in C35M3 annealed at $750{ }^{\circ} \mathrm{C}$ (Figure 5). Most likely microstructural changes occurred with annealing temperatures at or higher than $700^{\circ} \mathrm{C}$ with the $40 \%$ initial strain. Meanwhile, annealing at $650^{\circ} \mathrm{C}-1 \mathrm{~h}$ considerably softened C35M3, as shown in Figure 2. These results suggest that the intermediate annealing at $650^{\circ} \mathrm{C}$ for $1 \mathrm{~h}$ would sufficiently soften the materials to allow further deformation (i.e., next tube-drawing step) without grain coarsening via recrystallization during tube fabrications. 


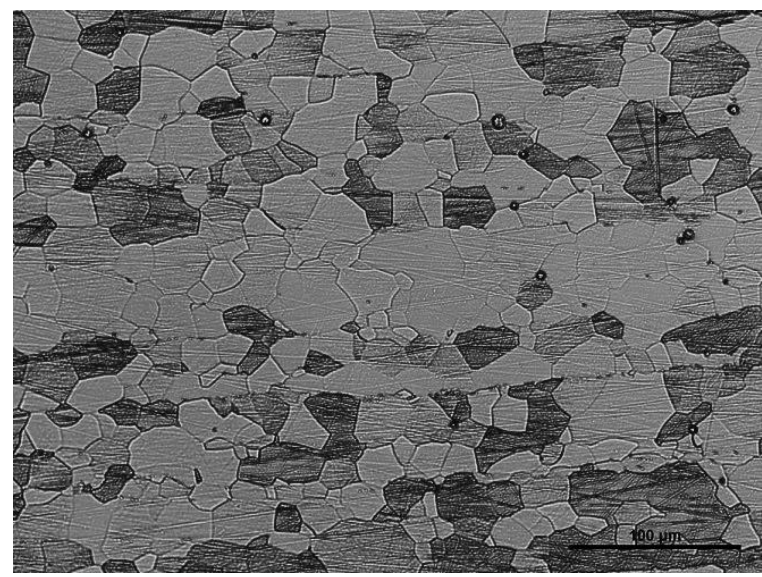

(a)

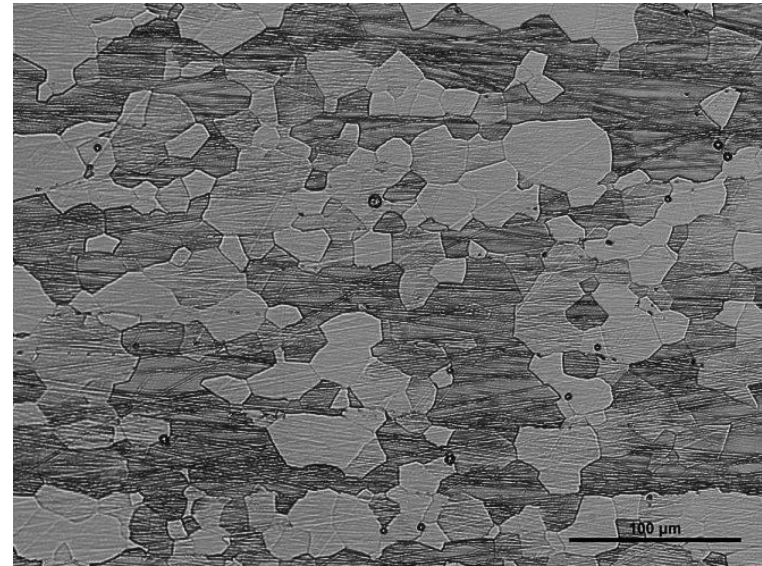

(c)

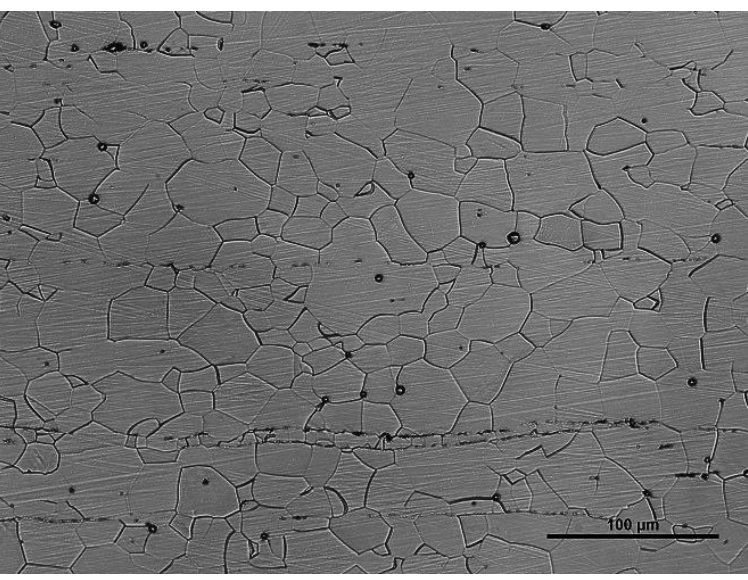

(b)

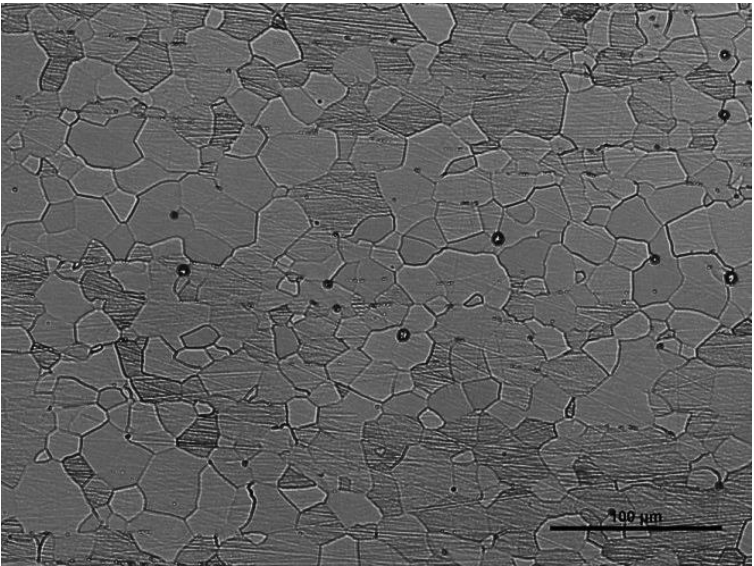

(d)

Figure 3. Optical micrographs of the C35M3 samples with the initial thickness reduction of 10\%: (a) asrolled; (b) annealed $4 \mathrm{~h}$ at $550^{\circ} \mathrm{C}$; (c) annealed $2 \mathrm{~h}$ at $650^{\circ} \mathrm{C}$; and (d) annealed $1 \mathrm{~h}$ at $750^{\circ} \mathrm{C}$. 


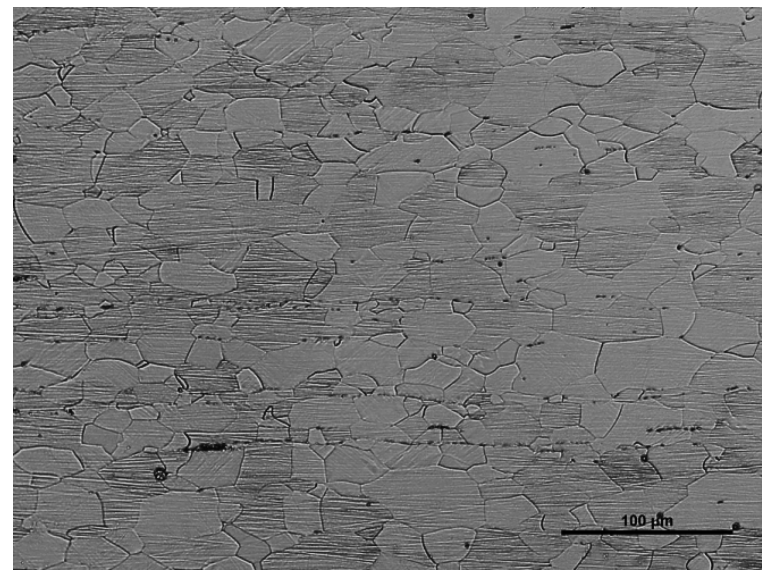

(a)

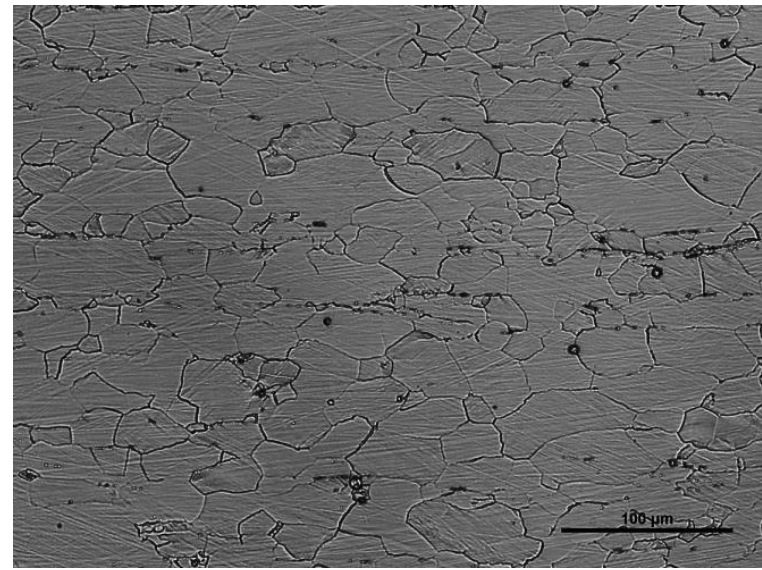

(c)

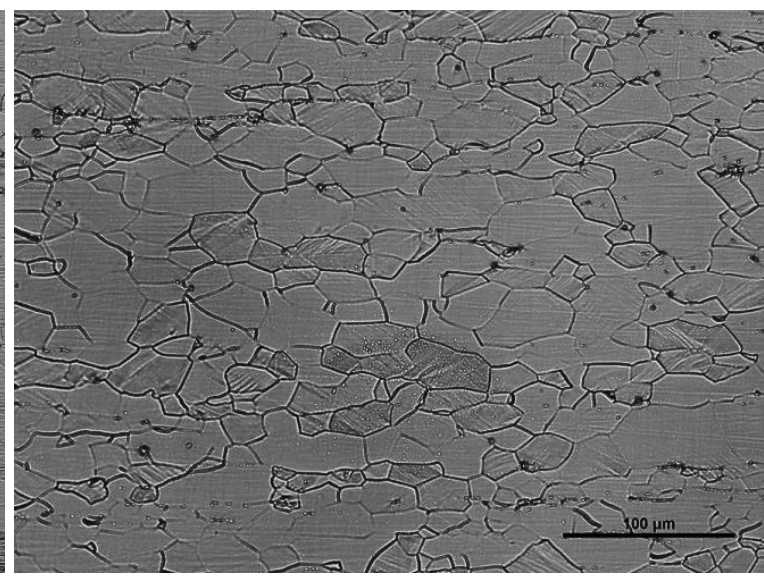

(b)

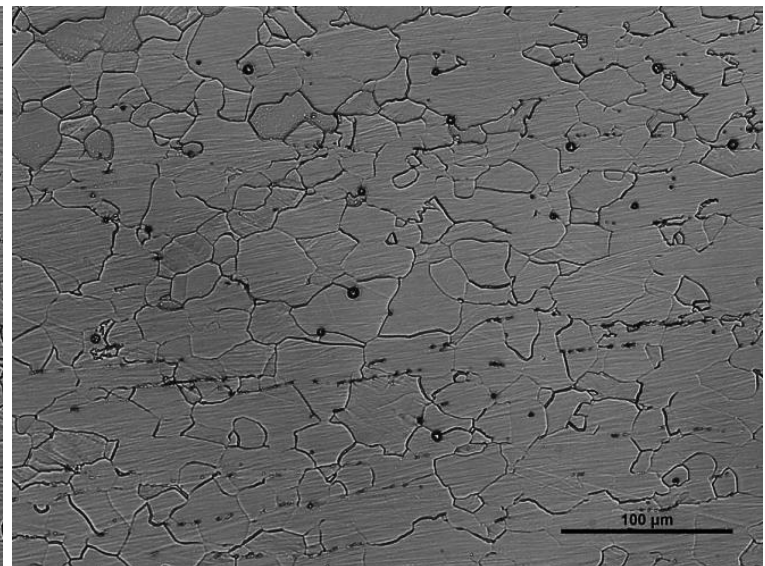

(d)

Figure 4. Optical micrographs of the C35M3 samples with the initial thickness reduction of 20\%: (a) asrolled; (b) annealed $4 \mathrm{~h}$ at $550^{\circ} \mathrm{C}$; (c) annealed $2 \mathrm{~h}$ at $700^{\circ} \mathrm{C}$; and (d) annealed $1 \mathrm{~h}$ at $750^{\circ} \mathrm{C}$. 


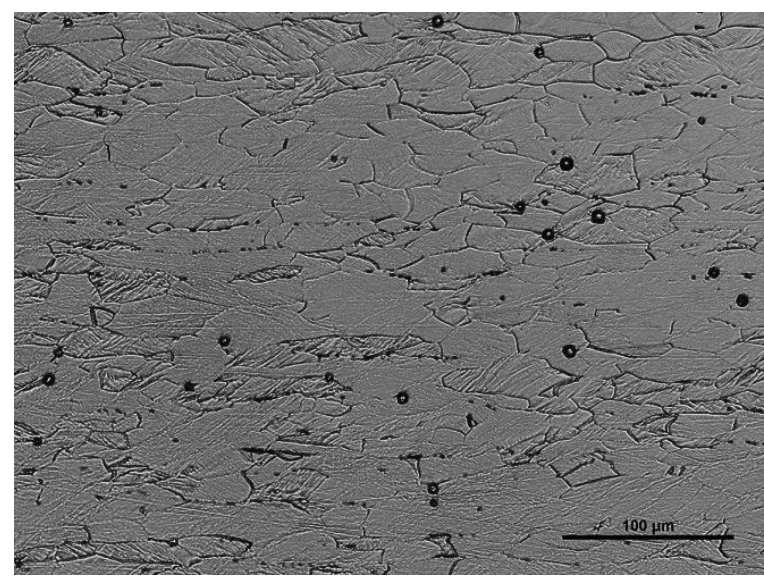

(a)

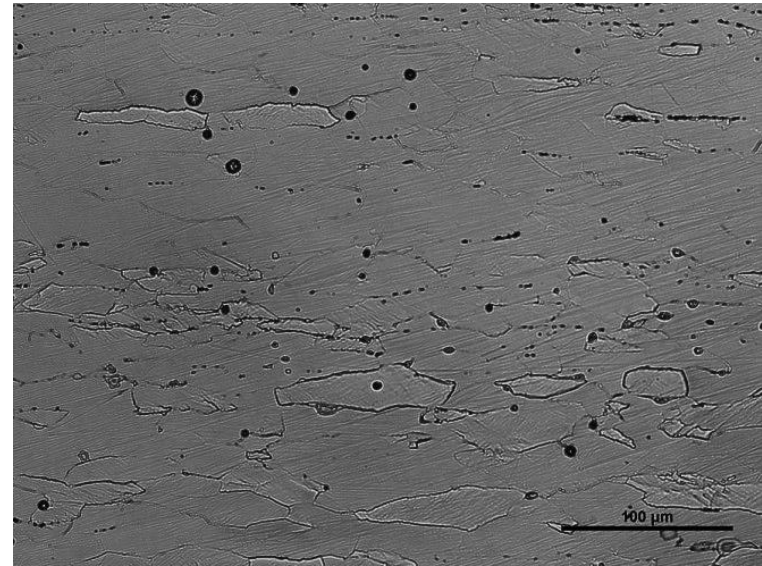

(c)

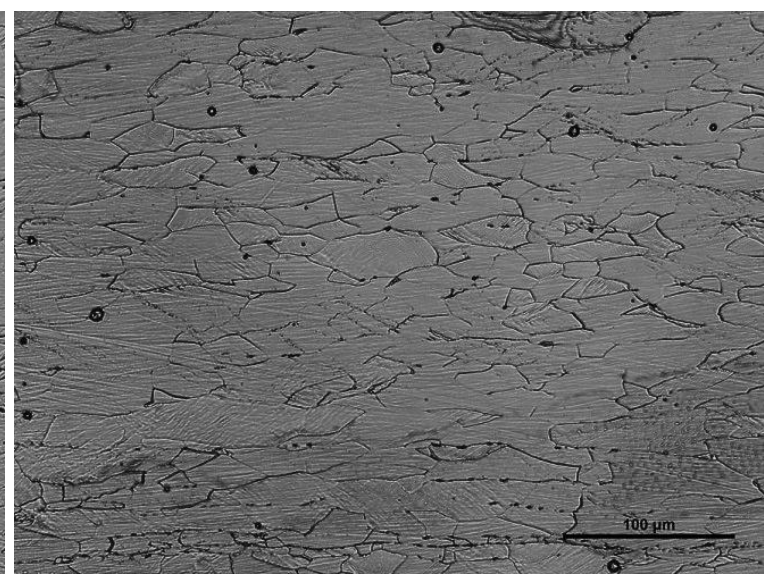

(b)

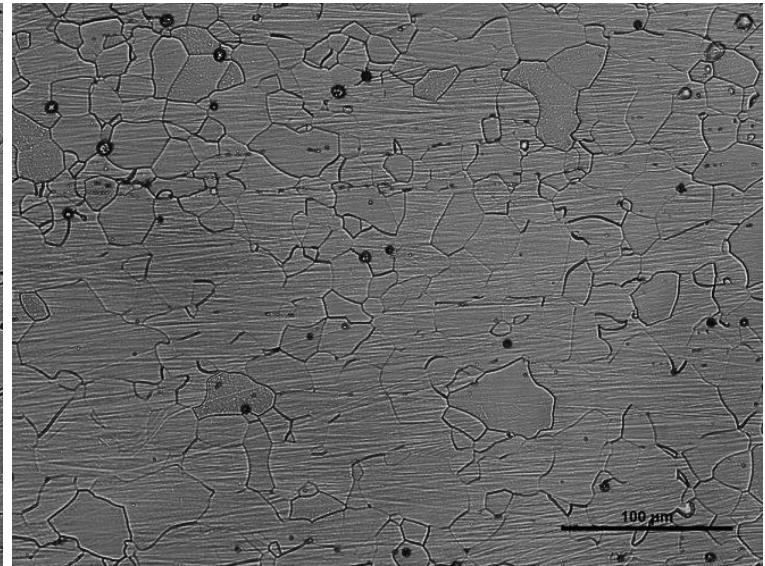

(d)

Figure 5. Optical micrographs of the C35M3 samples with the initial thickness reduction of 40\%: (a) asrolled; (b) annealed $4 \mathrm{~h}$ at $550^{\circ} \mathrm{C}$; (c) annealed $2 \mathrm{~h}$ at $650^{\circ} \mathrm{C}$; and (d) annealed $1 \mathrm{~h}$ at $750^{\circ} \mathrm{C}$.

In order to further demonstrate the effect of the selected intermediate annealing $\left(650^{\circ} \mathrm{C}-1 \mathrm{~h}\right)$ on the fabricability of C35M3, stepwise warm-rolling at $300^{\circ} \mathrm{C}$ was conducted to simulate a tube fabrication process. The warm-rolling schedule is illustrated in Figure 6. The starting plate (A0) had a thickness of $\sim 2.5 \mathrm{~mm}$. The strain per step was $\sim 11 \%$ to $26 \%$, reaching a total strain of $\sim 60 \%$ in step B4. The intermediate annealing $\left(650^{\circ} \mathrm{C}-1 \mathrm{~h}\right)$ was performed after each rolling step. Sub-sized-dog-bone tensile specimens with gage section dimensions of $\sim 0.5 \times 2 \times 10 \mathrm{~mm}$ were machined by using electrical discharge machining (EDM) from as-rolled and annealed C35M3 with the tensile axis parallel to the rolling direction.

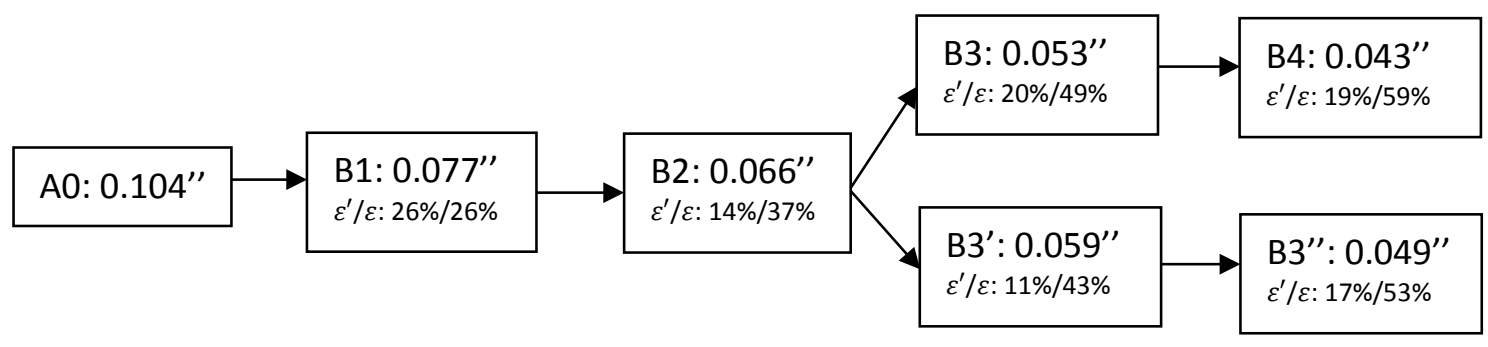

Figure 6. Warm-rolling schedule of $\mathrm{C} 35 \mathrm{M} 3$ at $300^{\circ} \mathrm{C}$ ( $\varepsilon^{\prime}$ : strain per step; $\varepsilon$ : total strain). 
Figure 7 shows the engineering stress vs. engineering plastic strain curves of as-rolled and annealed C35M3 samples, tested at room temperature. The plastic strain was obtained by subtracting the elastic strain from the engineering strain. Note that a suffix character ' $a$ ' in the sample ID was used to indicate annealed samples (e.g., B1a). The starting C35M3 plate (A0) had a uniform strain of $~ 13 \%$ with a yield stress of $\sim 490 \mathrm{MPa}$. However, after warm-rolling, the as-rolled C35M3 specimens exhibited increased yield stress ( $>\sim 800 \mathrm{MPa}$ ) while the stress immediately dropped after yielding, indicating almost no uniform deformation, as shown in Figure 7a. However, after utilizing intermediate annealing (Figure 7b), the yield stress decreased to a range of 576-680 MPa with improved uniform elongation in the range of 7 8.5\%. Figure 8 summarizes the annealing effects on the tensile properties and Vickers hardnesses of the as-rolled and annealed C35M3. A clear relationship is shown between the tensile properties and the hardnesses, indicating that the hardness measurements can be used to determine fabricability after annealing. Optical micrographs of A0, B1, and B3a are displayed in Figure 9 - clearly showing that the grains gradually elongated along the rolling direction from A0 to B3a and no grain growth or recrystallization occurred in B3a.

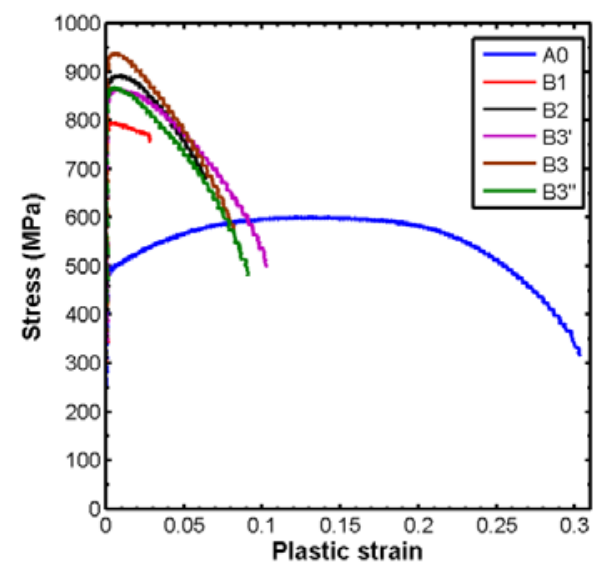

(a)

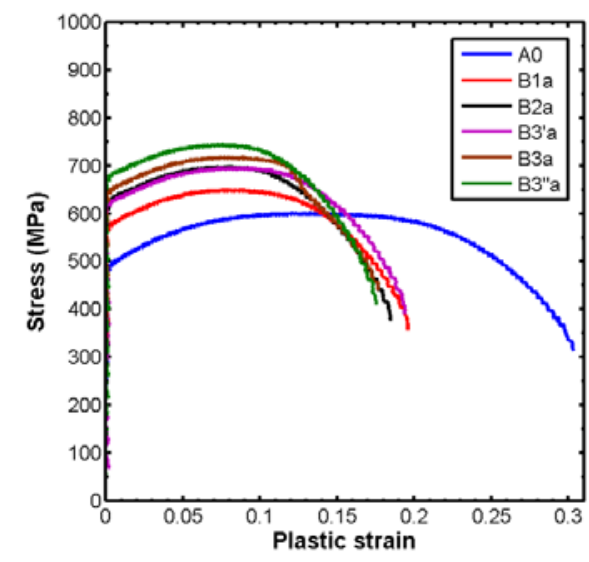

(b)

Figure 7. Stress vs. strain curves of C35M3 for (a) as-rolled and (b) annealed samples. The corresponding curve of initial C35M3 plate (A0) is included for comparison.

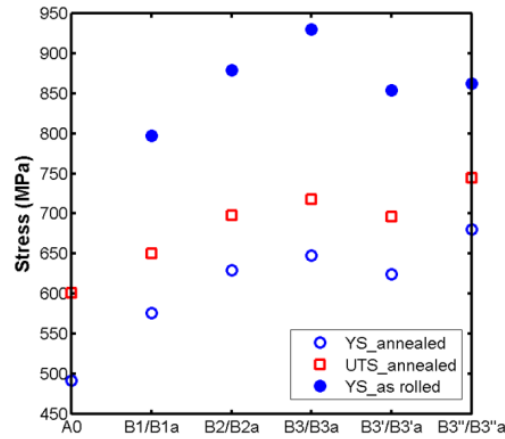

(a)

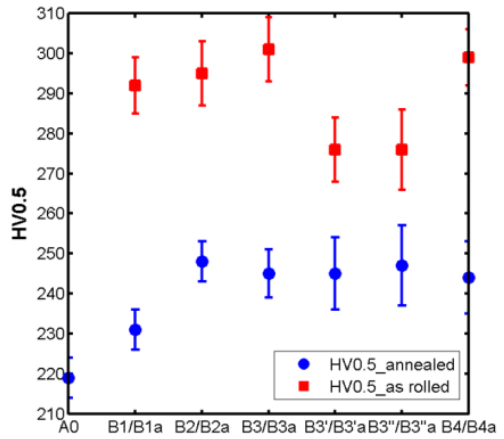

(b)

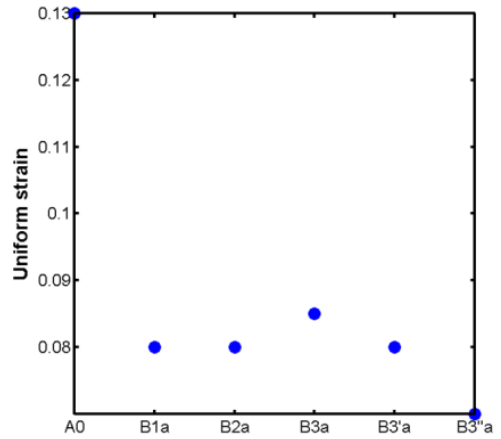

(c)

Figure 8. Effects of annealing $\left(650^{\circ} \mathrm{C}-1 \mathrm{~h}\right)$ on (a) tensile properties, (b)Vickers hardness, and (c) plastic uniform strain for rolled C35M3. 


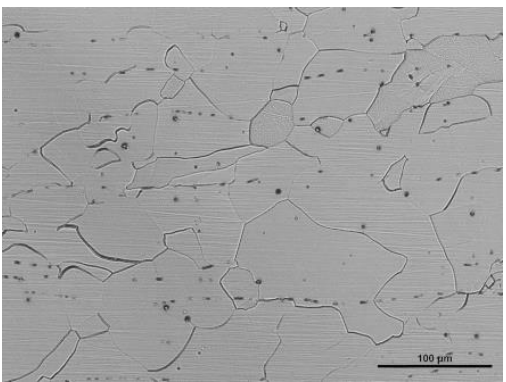

(a)

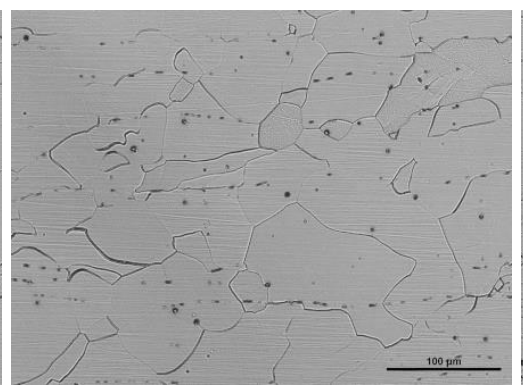

(b)

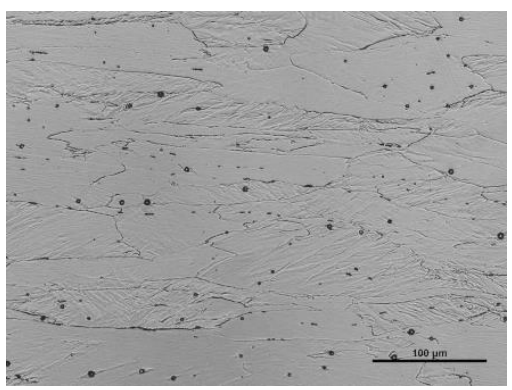

(c)

Figure 9. Optical micrographs of the stepwise rolled and annealed C35M3; (a) A0, (b) B1, and (c) B3a.

\subsection{Microstructure Evolution during Stepwise Rolling of C35M4 (Simulating Tube-Drawing Process)}

Stepwise warm-rolling at $400^{\circ} \mathrm{C}$ with intermediate annealing $\left(650^{\circ} \mathrm{C}-1 \mathrm{~h}\right.$ or $\left.871^{\circ} \mathrm{C}-30 \mathrm{~min}\right)$ was conducted to simulate tube fabrication of C35M4 (Gen II, Fe-13Cr-5.2Al-2Mo base). The microstructure evolution and mechanical properties during the stepwise rolling were evaluated. The important findings are summarized below:

1) With intermediate annealing at $650^{\circ} \mathrm{C}$ for $1 \mathrm{~h}$, C35M4 maintained deformed, non-recrystallized microstructures with grains elongated in the rolling direction. The typical BCC texture consisting of $\gamma$-fibre (major) and $\alpha$-fibre (minor) were developed. The residual strain gradually accumulated as the stepwise rolling proceeded.

2) With intermediate annealing at $871^{\circ} \mathrm{C}$ for $30 \mathrm{~min}$, C35M4 exhibited recrystallization and grain growth during the stepwise rolling, resulting in a coarse grain structure with an average equivalent diameter of $\sim 200 \mu \mathrm{m}$. This is not suitable for thin-wall tube production since such coarse grains would cause non-uniform deformation, leading to non-uniform wall thickness.

3) The results demonstrated the coarse grain formation observed at the first trial tube fabrication of C35M2 in FY2015 [12].

4) The intermediate annealing at $650^{\circ} \mathrm{C}$ for $1 \mathrm{~h}$ is considered an optimum intermediate anneal for tube fabrication of C35M4.

Two plates were stepwise warm-rolled at $400^{\circ} \mathrm{C}$ with different intermediate annealing steps after each rolling step: (A) $1 \mathrm{~h}$ at $650^{\circ} \mathrm{C}$ and (B) $30 \mathrm{~min}$ at $871^{\circ} \mathrm{C}$. A total of 16 rolling passes were applied with a nominal $10 \%$ thickness reduction per pass. Small coupons for microstructural characterization and hardness measurements were sectioned by EDM after each pass. The measured strain per pass and total accumulated strain are plotted in Figure 10 . The measured strain per pass $(6.5 \%-10.3 \%)$ resulted in a final plate thickness of $0.85 \mathrm{~mm}$ (total strain $\sim 76.8 \%$ ) after the $16^{\text {th }}$ pass. In the following section, the asrolled (annealed) samples after the $n^{\text {th }}$ pass are referred as $\mathrm{An}$ (An') or $\mathrm{Bn}$ (Bn'). 


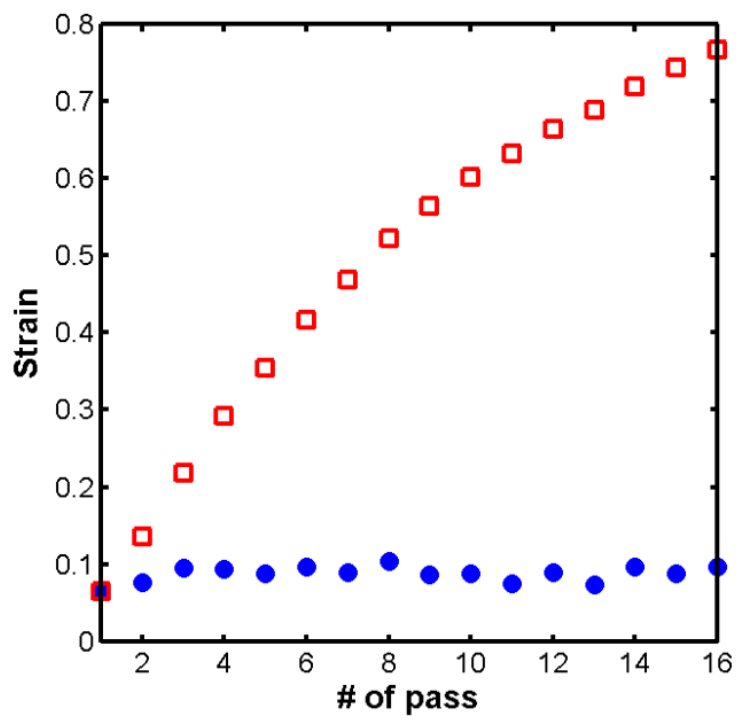

Figure 10. Strain per pass (blue) and total strain (red) in the stepwise warm rolling at $400^{\circ} \mathrm{C}$ of C35M4.

\subsubsection{Initial state prior to stepwise rolling}

A hot-extruded and annealed C35M4 bar sample with an equiaxed grain structure (grain size of 100um) was prepared. The bar sample was identical to the material that was provided to Rhenium Alloys, Inc. for tube production. Plate samples were sectioned from the extruded bar as starting material for the study. The Vickers hardness prior to stepwise rolling (A0) was $207 \pm 6$. Figure 11 displays the tensile properties of $\mathrm{A} 0$ at $24-800^{\circ} \mathrm{C}$. The yield stress of C35M4 decreased from $490 \mathrm{MPa}$ at room temperature to $89 \mathrm{MPa}$ at $800^{\circ} \mathrm{C}$. The ultimate tensile stress followed a similar trend as a function of temperature. The C35M4 showed considerable deformability with a uniform strain larger than $10 \%$ below $600^{\circ} \mathrm{C}$. The uniform strain decreased with temperature above $400^{\circ} \mathrm{C}$, exhibiting $\sim 2 \%$ uniform strain at $800^{\circ} \mathrm{C}$, indicating potential deformation instability at elevated temperatures. However, the failure strain increased as the test temperature increased.

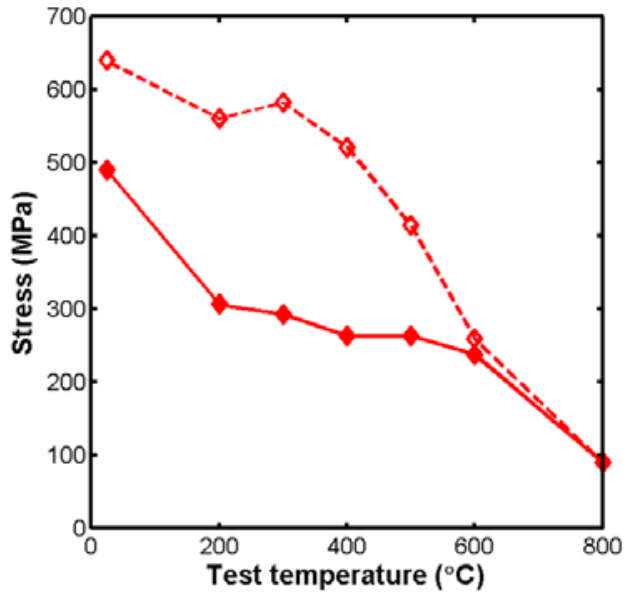

(a)

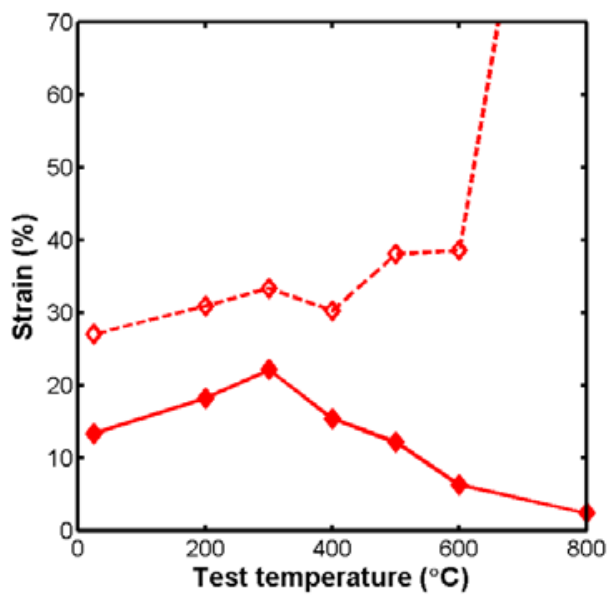

(b)

Figure 11 . Tensile properties of A0 in a temperature range of $24-800^{\circ} \mathrm{C}$ : (a) yield stress (filled symbols)/ultimate tensile stress (open symbols) and (b) uniform strain (filled symbols) and failure strain (open symbols). 


\subsubsection{Microstructures with the intermediate annealing at $650^{\circ} \mathrm{C}$}

Figure 12 shows the inverse pole figure (IPF) maps and (001), (110), and (111) pole figures of A1', A7', and A16', obtained from SEM-EBSD analysis. Note: the rolling direction is parallel to the vertical axis of the IPM maps. As shown in the IPF maps, grains gradually elongated in the rolling direction as the stepwise rolling proceeded. The equivalent average grain diameter slightly decreased from $74 \pm 28 \mu \mathrm{m}$ (A1') to $59 \pm 33 \mu \mathrm{m}$ (A16'), while the grain aspect ratio significantly decreased from $0.57 \pm 0.11$ (A1') to $0.12 \pm 0.09$ (A16'). It is interesting to note that the grain aspect ratio reduction from A1' to A16' was 0.79, which was close to the total thickness reduction. Based on the (001), (110), and (111) pole figures, certain textures were developed in the stepwise rolling. The texture consisting of $\gamma$-fibre $(\{111\}<110>$, major) and $\alpha$-fibre ( $\{001\}<110>$, minor), common in rolled bcc materials, were observed. Subgrains with a size on the order of $1 \mu \mathrm{m}$ were observed in A16', as shown in Figure 13.

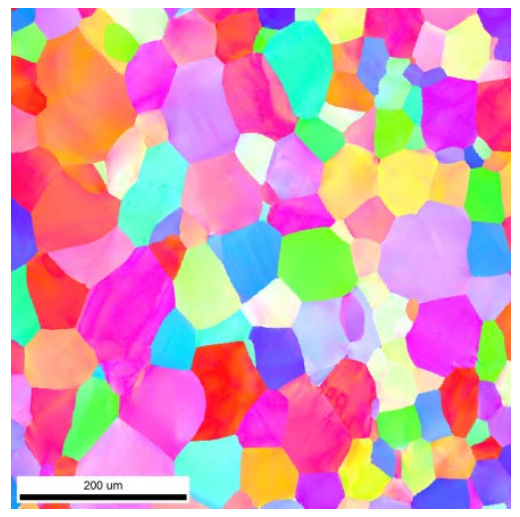

(a)

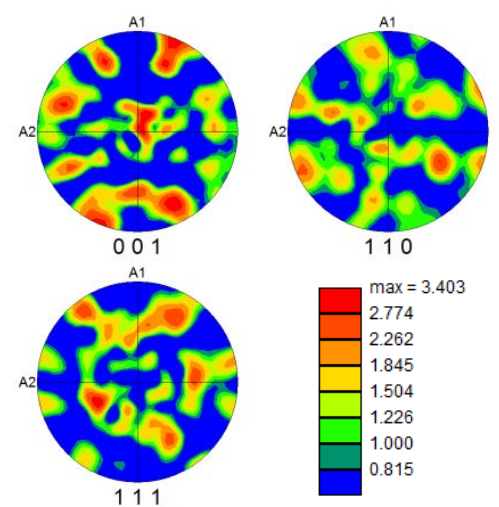

(d)

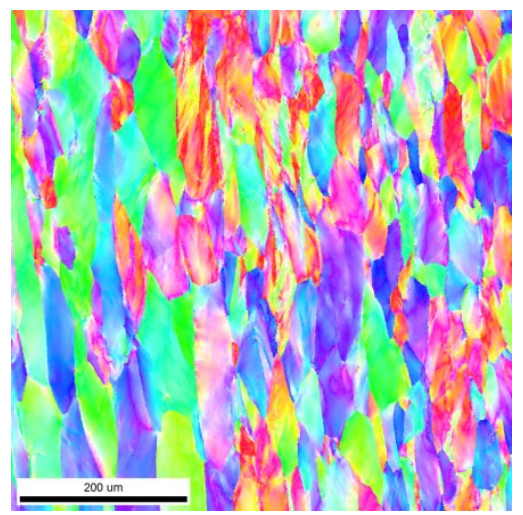

(b)

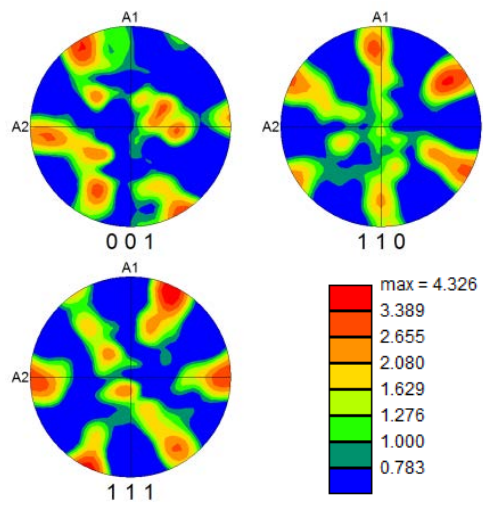

(e)

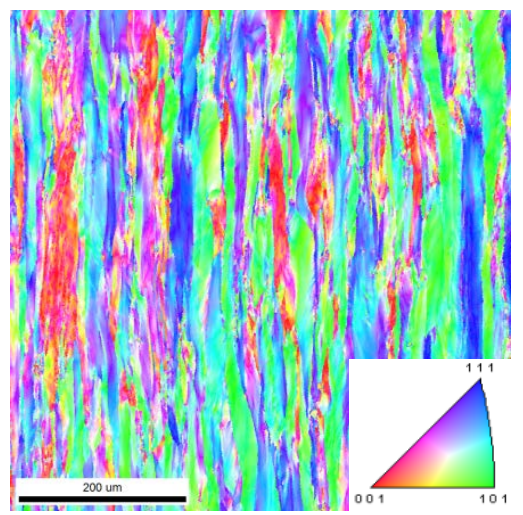

(c)
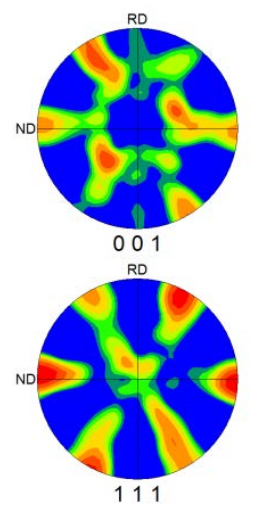

(f)

Figure 12. Inverse Pole Figure maps and (001), (110), and (111) pole figures of A1' (a \& d), A7' (b \& e), and A16' (c \& f). The EBSD step sizes were 1.0, 0.8, and 0.8 $\mu \mathrm{m}$ for A1', A7', and A16', respectively. Note that (a), (b), and (c) have the same size scale. 


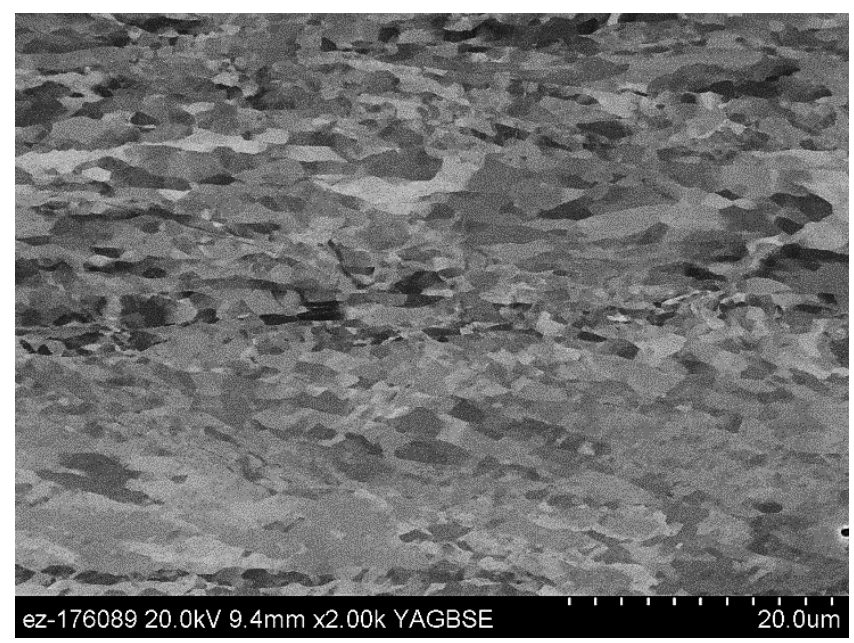

Figure 13. Backscattered electron image of subgrains in A16’.

\subsubsection{Microstructures with the intermediate annealing at $871^{\circ} \mathrm{C}$}

The IPF maps and (001), (110), and (111) pole figures of B1', B7', and B16' are displayed in Figure 14. In the IPF maps, instead of having deformed and elongated grains, coarse grains were observed in B7' and B16', similar to the results of the first tube fabrication trial in FY2015 [12]. The average equivalent grain diameter increased from $73 \pm 29 \mu \mathrm{m}$ (B1') to $172 \pm 59 \mu \mathrm{m}$ (B16'). The grain aspect ratio slightly dropped from $0.57 \pm 0.10$ (B1') to $0.42 \pm 0.09$ (B7'). However, it went back to $0.49 \pm 0.15$ in B16'. No clear texture tendency was observed in B7' and 16', as demonstrated in the pole figures.

\subsubsection{Mechanical properties after the stepwise rolling}

The Vickers hardness of as-rolled and annealed C35M4 after the $1^{\text {st }}, 4^{\text {th }} \cdot 7^{\text {th }}$, and $16^{\text {th }}$ passes are plotted in Figure 15. The Vickers hardness after the $1^{\text {st }}$ rolling pass increased from $207 \pm 6$ (A0) to 250 (A1 and $\mathrm{B} 1)$. Note that the hardness of the as-rolled samples was always higher than the starting material and the highest hardness reached was $\sim 280$. The intermediate annealing always lowered the hardness of the rolled C35M4 samples, as shown with the open symbols in Figure 15 . With the intermediate annealing at $650^{\circ} \mathrm{C}$, the hardness of the annealed C35M4 samples increased initially and saturated at 240 , indicating that the accumulated residual strain balanced with the recovering process (without recrystallization). The hardness of the annealed samples maintained an almost constant value of $\sim 210$ with the intermediate anneal at $871^{\circ} \mathrm{C}$. Based on the microstructural characterization and Vickers hardnesses, it is concluded that the intermediate anneal of $871^{\circ} \mathrm{C}, 30 \mathrm{~min}$ is not suitable for tube drawing of C35M4 because it would not prevent recrystallization and grain growth. 


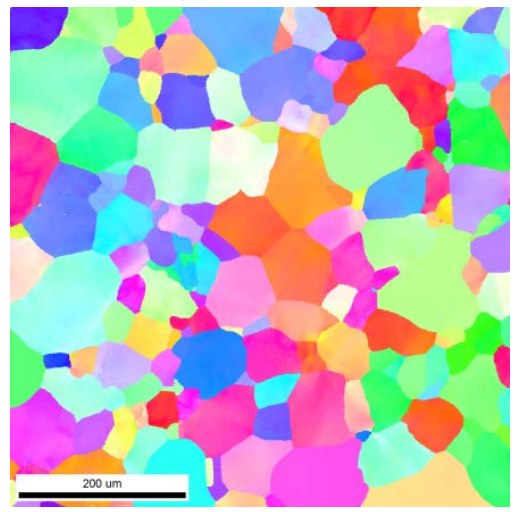

(a)

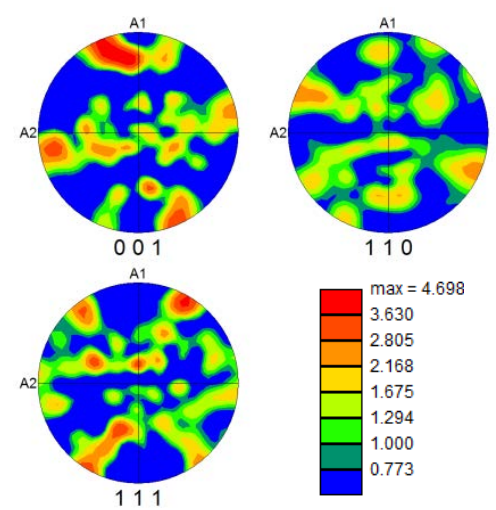

(d)

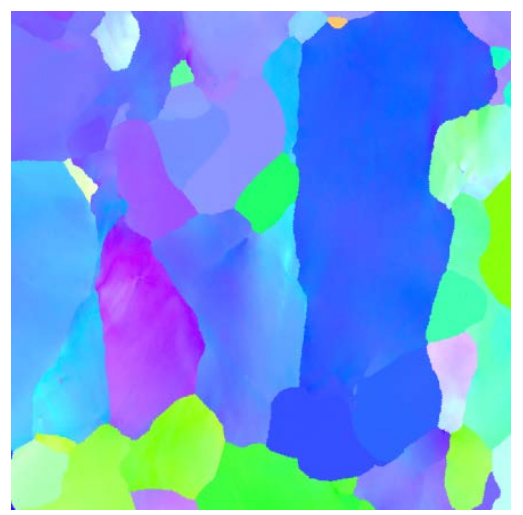

(b)

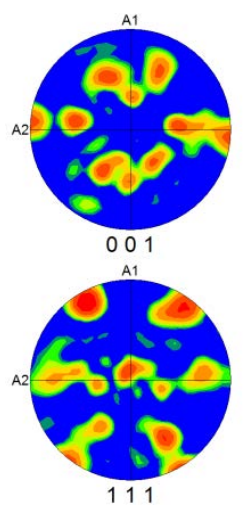

(e)

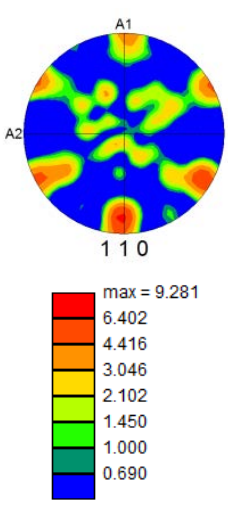

e)

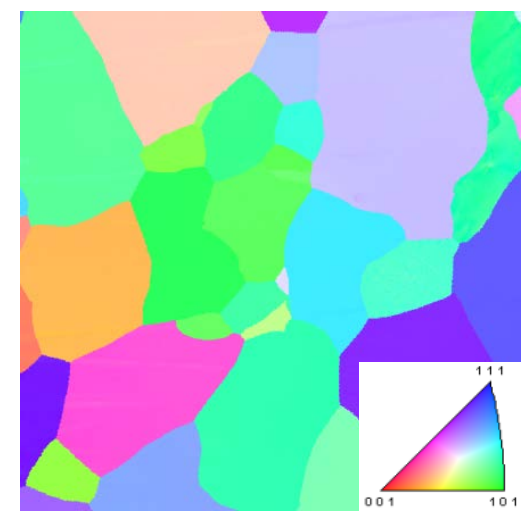

(c)

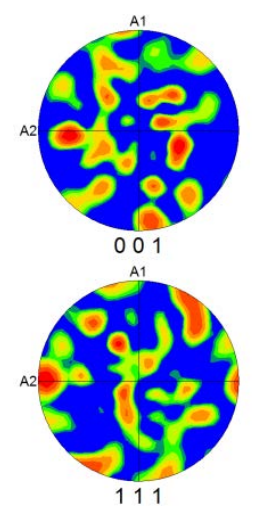

(f)

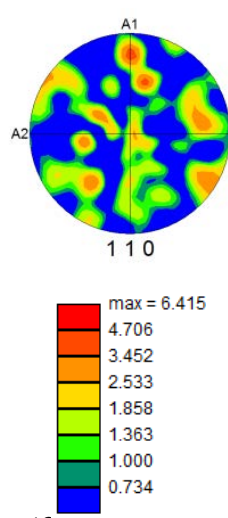

Figure 14. IPF maps and (001), (110), and (111) pole figures of B1' (a \& d), B7' (b \& e), and B16' (c \& f). The EBSD step sizes were 1.0, 0.8, and 0.8 $\mu \mathrm{m}$ for A1', A7', and A16', respectively. Note that (a), (b), and (c) have the same size scale.

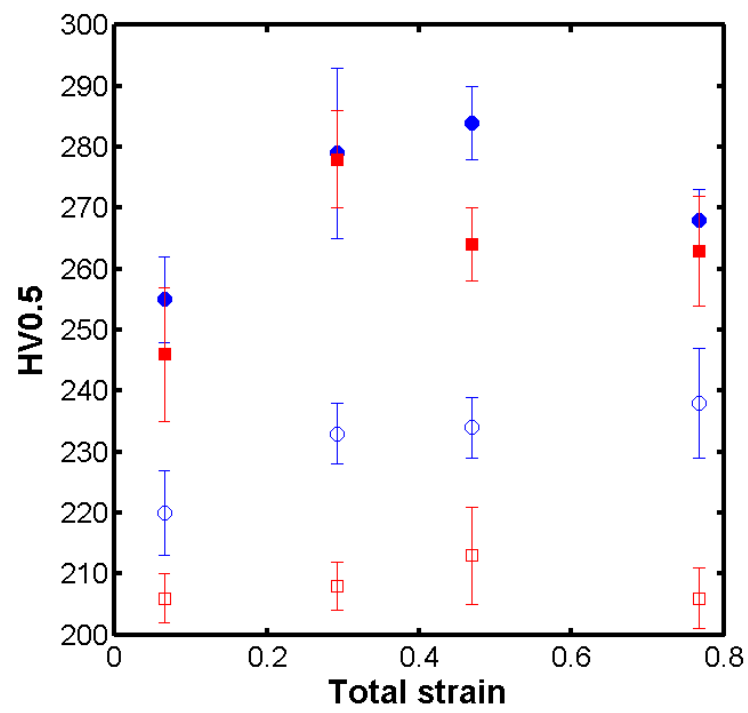

Figure 15. Vickers hardness of as-rolled (filled markers) and annealed (unfilled markers) C35M4 samples after the $1^{\text {st }}, 4^{\text {th }}, 7^{\text {th }}$, and $16^{\text {th }}$ passes (blue: $650^{\circ} \mathrm{C}-1 \mathrm{~h}$; red: $871^{\circ} \mathrm{C}-30 \mathrm{~min}$ ). 


\subsection{Microstructural Control of Nb-containing FeCrAl Alloys}

The addition of $\mathrm{Nb}$ to $\mathrm{FeCrAl}$ alloys is known to promote the formation of sub-micron size $\mathrm{Fe}_{2} \mathrm{Nb}$-Laves phase particles during warm- or hot-processing which effectively stabilize the deformed microstructure and improve mechanical properties at both room and elevated temperatures [11,12]. In order to utilize the beneficial effect of such Laves-phase formation, it is important to understand the relationship among the alloy composition, microstructure, deformability, and the stability of the deformed microstructure. In this section, the recovery and recrystallization behaviors of several Nb-containing $\mathrm{FeCrAl}$ alloys at $600-900^{\circ} \mathrm{C}$ were investigated in order to understand the effects of $\mathrm{Nb}$ on the microstructural stability and mechanical properties of FeCrAl alloys. Based on the results, it is concluded that; (1) the recovery and recrystallization kinetics of the warm-rolled materials is not sensitive to the Cr content in a range from 11 to 13 wt.\%; and (2) the thermal stability of deformed microstructures increases with increased $\mathrm{Nb}$ content up to $1 \mathrm{wt} . \%$, whereas the stability becomes less dependent on the $\mathrm{Nb}$ content with additions greater than $1 \mathrm{wt} . \%$. Optimization of the process conditions for tube-production is still required because the higher strength, compared to Mo-containing FeCrAl alloy, needs to be balanced with tube fabricability. The optimization effort is in progress.

Five different Nb-containing FeCrAl alloys (C16N, C26N, C36N, C36N2, and C36N3, Fe-\{11-13\}Cr$6 \mathrm{Al}-\{0.7-2\} \mathrm{Nb}$ base) were investigated. Some results of C36M2 (Fe-13Cr-6Al-2Mo base) were included for comparison. All alloys were hot-rolled and annealed at $1200^{\circ} \mathrm{C}$ to prepare the starting plate materials with $2.5 \mathrm{~mm}$ thickness and a grain size of $\sim 100 \mu \mathrm{m}$. The starting plates were warm-rolled at $300^{\circ} \mathrm{C}$ with $10 \%$ thickness reductions per pass, total $\sim 80 \%$ thickness reductions. Warm-rolled plates were sectioned into small pieces and then annealed at $600-900^{\circ} \mathrm{C}$ for durations up to $504 \mathrm{~h}$.

\subsubsection{Microstructures of deformed samples}

As shown in Figure 16a, as-rolled samples exhibited a band-like microstructure consisting of grains elongated in the direction of rolling. The IPF map of the as-rolled C36N in Figure 16b showed a variation of misorientation in each elongated grain, indicating deformation inhomogeneity within and among grains. A few Laves phase particles with a volume fraction of $1.6 \pm 0.2 \%$ and an equivalent radius of $\sim 1.2 \pm 0.4 \mu \mathrm{m}$ were observed in the as-rolled C36N2. Only small amounts of Laves phase particles were observed in the as-rolled C36N, indicating that the $\mathrm{Nb}$ solution limit in bcc-Fe matrix at $1200^{\circ} \mathrm{C}$ was close to $1 \mathrm{wt} . \%$ in the current $\mathrm{FeCrAl}$ alloys. Cracks were occasionally observed in the Laves phase particles (Figure 16c), but they did not propagate into the bcc-Fe matrix, suggesting that the brittleness of the particles would not degrade the deformability of the alloys. The as-rolled Vickers hardnesses were $378 \pm 8$ (C16N), $386 \pm 7$ (C26N), $394 \pm 6$ (C36N), $423 \pm 8$ (C36N2), $382 \pm 11$ (C36N3), and $359 \pm 12$ (C36M2). 


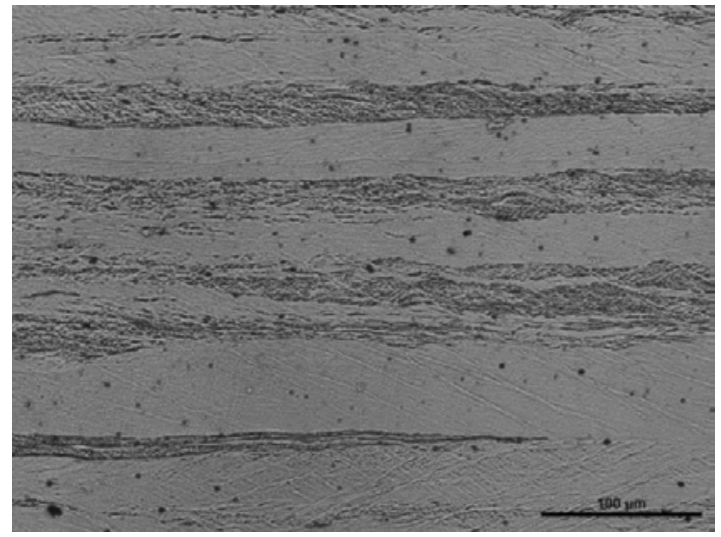

(a)

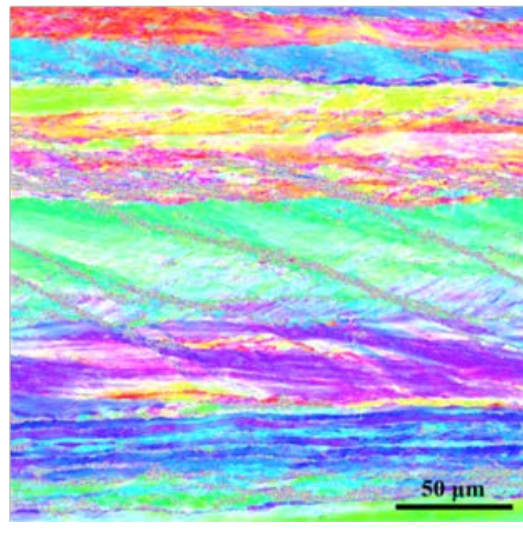

(b)

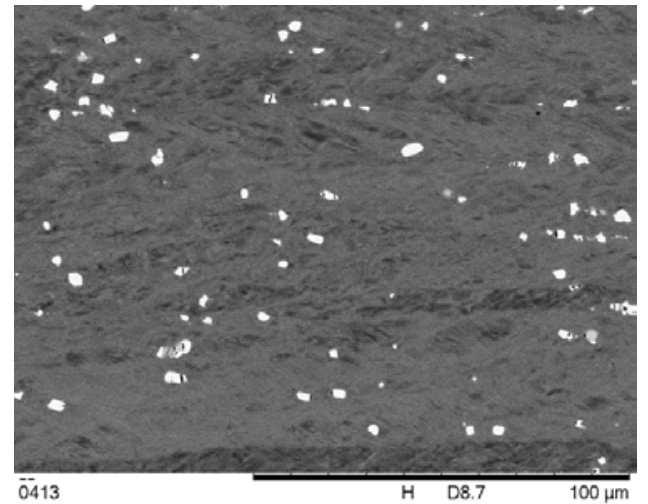

(c)

Figure 16. (a) Typical optical micrographs of as-rolled specimens showing band-like structures along the rolling direction; (b) IPF map of the as-rolled C36N sample; and (c) back-scattered electron image of the as-rolled C36N2 sample showing Laves phase particles (with bright contrast).

\subsubsection{Microstructures of annealed samples}

Recovery and recrystallization occurred during annealing. Figure 17 shows the recrystallization initiation time of the studied alloys at $650-800^{\circ} \mathrm{C}$ (observed under optical microscopy). C16N, C26N, C36N, and C36N2 had similar recrystallization kinetics, and thus, only the results of C36N were displayed in Figure 17. By comparing the recrystallization initiation time of C36M2 $(0 \mathrm{Nb}), \mathrm{C} 36 \mathrm{~N} 3(0.7 \mathrm{Nb})$, and C36N (1 or $2 \mathrm{Nb}$ ), it is clear that the $\mathrm{Nb}$ addition in $\mathrm{FeCrAl}$ alloys significantly stabilizes the deformed microstructures up to $1 \mathrm{wt} . \%$, and no further stabilization is expected with more than $1 \mathrm{wt} . \%$ addition. 


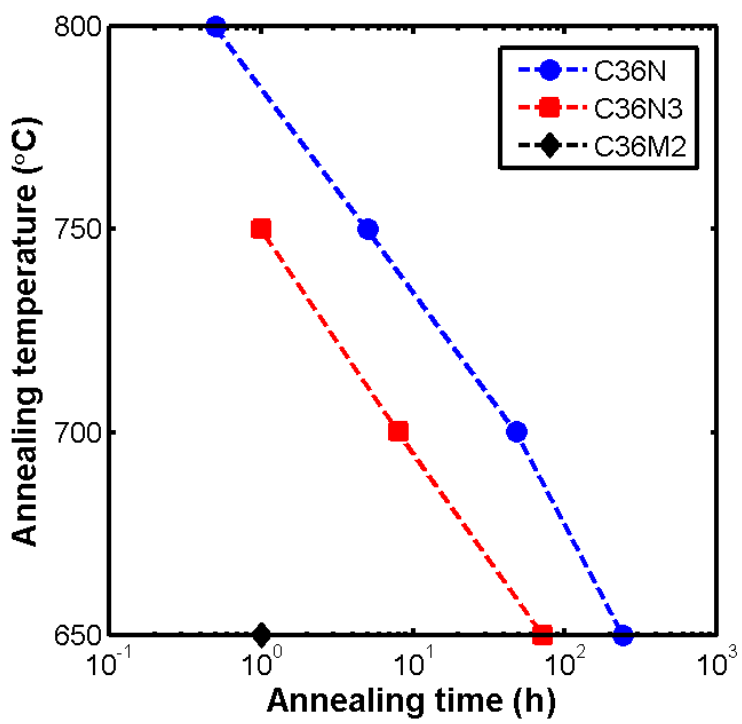

Figure 17. Initiation of recrystallization at $650-800^{\circ} \mathrm{C}$ observed by optical microscopy for $\mathrm{C} 36 \mathrm{~N}(1 \mathrm{Nb})$, C36N3 (0.7Nb), and C36M2 (0Nb).

Microstructural details and mechanical properties after annealing will be discussed next. The IPF map of $\mathrm{C} 36 \mathrm{~N}$ after annealing for $1 \mathrm{~h}$ at $700^{\circ} \mathrm{C}$ is displayed in Figure 18a. Note that the rolling direction is parallel to the horizontal axis of the IPF maps. Some areas had larger rotations compared to the surroundings, which were likely heavily deformed during warm-rolling. These areas were found to have equiaxed subgrains, $\sim 1 \mu \mathrm{m}$ in size, with high-angle boundaries upon further annealing at $700^{\circ} \mathrm{C}$, as shown in Figure 18b. Moreover, elongated recrystallized grains ( $10 \mu \mathrm{m}$ in size) formed by consuming the fine grains. Several grains having low internal misorientation did not show clear sub-boundaries in the IPF map (Figure 18b). SEM back-scattered electron images of the annealed C36N indicated that the Laves phase particles (bright contrast) pinned grain/subgrain boundaries, as shown in Figure 18c and Figure 18d. It is interesting to note that two distinct microstructures were observed in Figure 18c; one with mostly equiaxed subgrains ( $\sim 1 \mu \mathrm{m}$ in size) with less and larger Laves phase particles, and the others with fine elongated subgrains with smaller Laves phase particles.

Recrystallization initiated quickly when annealed at higher temperatures (e.g., 800 and $900^{\circ} \mathrm{C}$ ). Figure 19a shows the mixed microstructures of $\mathrm{C} 36 \mathrm{~N}$ annealed for $24 \mathrm{~h}$ at $800^{\circ} \mathrm{C}$. Reaction fronts (high-angle grain boundaries) advancing into non-recrystallized region were observed (marked by arrows in Figure 19). C36N had smaller recrystallized grains at $900^{\circ} \mathrm{C}$ than those at $800^{\circ} \mathrm{C}$ as can be seen by comparing Figure 19a and Figure 19b. Figure 19b also shows recrystallized grains $(\sim 23.5 \pm 14.4 \mu \mathrm{m}$ in equivalent diameter) elongated in the rolling direction with a grain aspect ratio of $0.3 \pm 0.1$. There were still a few non-recrystallized grains (marked by arrows in Figure 19b) with subgrains in C36N annealed for 24h at $900^{\circ} \mathrm{C}$. The (001), (110), and (111) pole figures of Figure 19b are displayed in Figure 19c. Based on these pole figures, no strong texture was observed in recrystallized grains of $\mathrm{C} 36 \mathrm{~N}$ after annealing for $24 \mathrm{~h}$ at $900^{\circ} \mathrm{C}$. Back-scattered electron images of C36N samples annealed at $900^{\circ} \mathrm{C}$ for $1 \mathrm{~h}$ and $72 \mathrm{~h}$ are shown in Figure 20a and Figure 20b, respectively. In Figure 20a, a large number of Laves phase particles remained within recrystallized grains. However, after annealing for $72 \mathrm{~h}$ at $900^{\circ} \mathrm{C}$, most of Laves phase particles were distributed along grain boundaries with few Laves phase particles within recrystallized grains. 


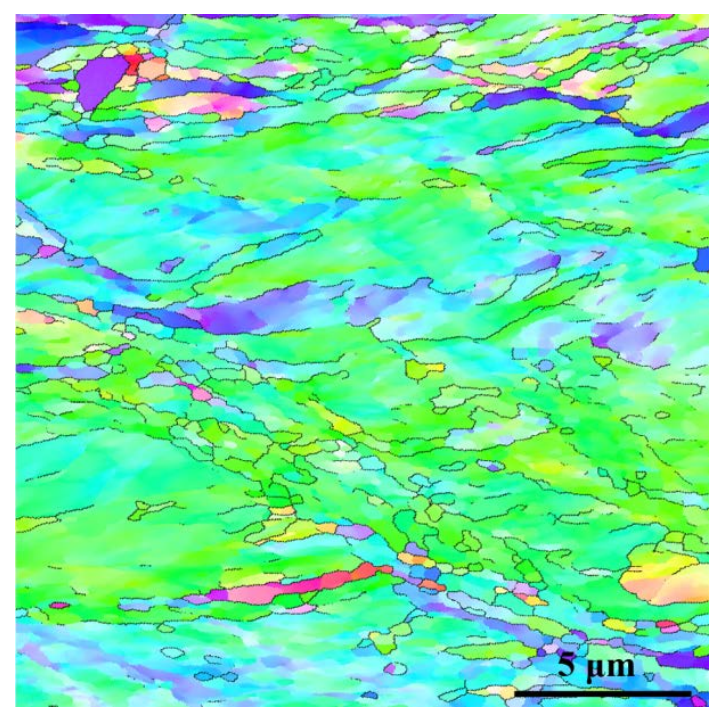

(a)

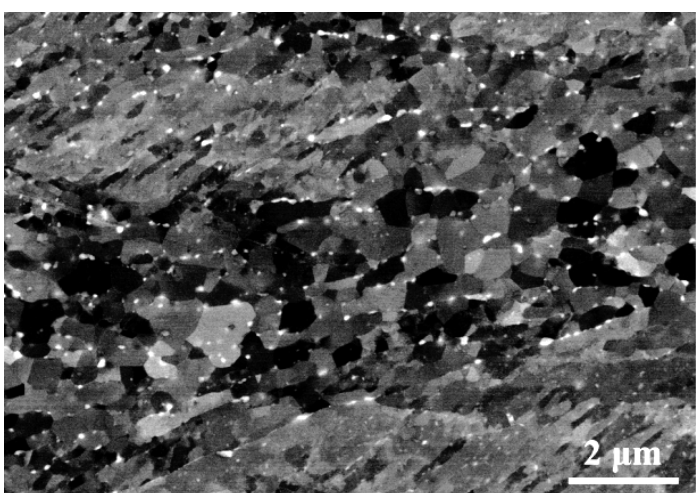

(c)

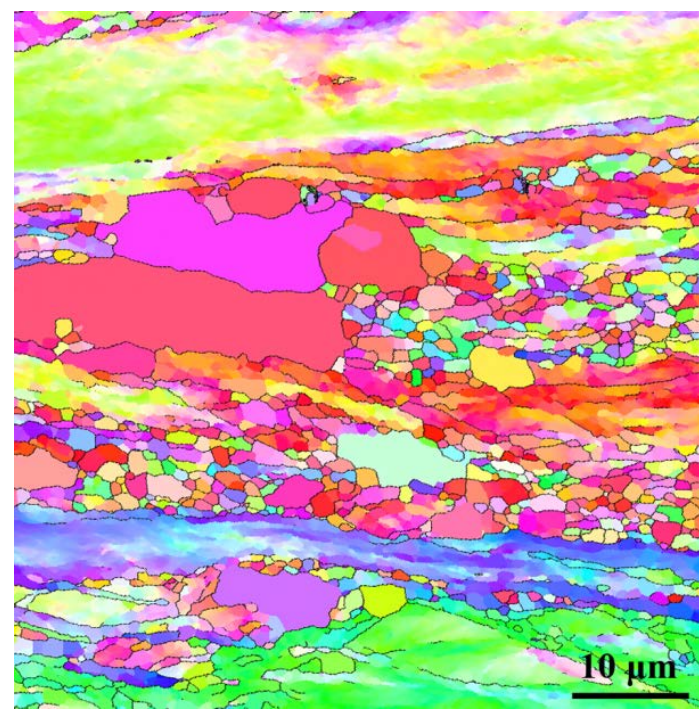

(b)

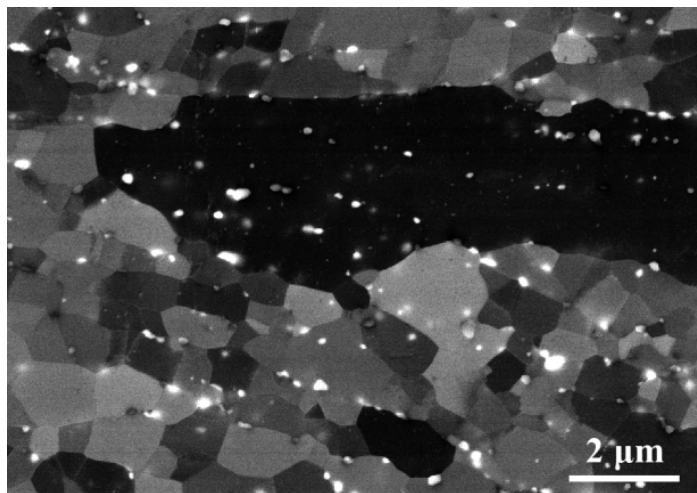

(d)

Figure 18. IPF maps of C36N samples after annealing at $700^{\circ} \mathrm{C}$ for (a) $1 \mathrm{~h}$ and (b) $96 \mathrm{~h}$. Grain boundaries with misorientation greater than $15^{\circ}$ would be marked by black lines. Backscattered electron images shows Laves phase particles (bright contrast) and subgrains in $\mathrm{C} 36 \mathrm{~N}$ samples annealed at $700^{\circ} \mathrm{C}$ for (c) $8 \mathrm{~h}$ and (d) $96 \mathrm{~h}$. 


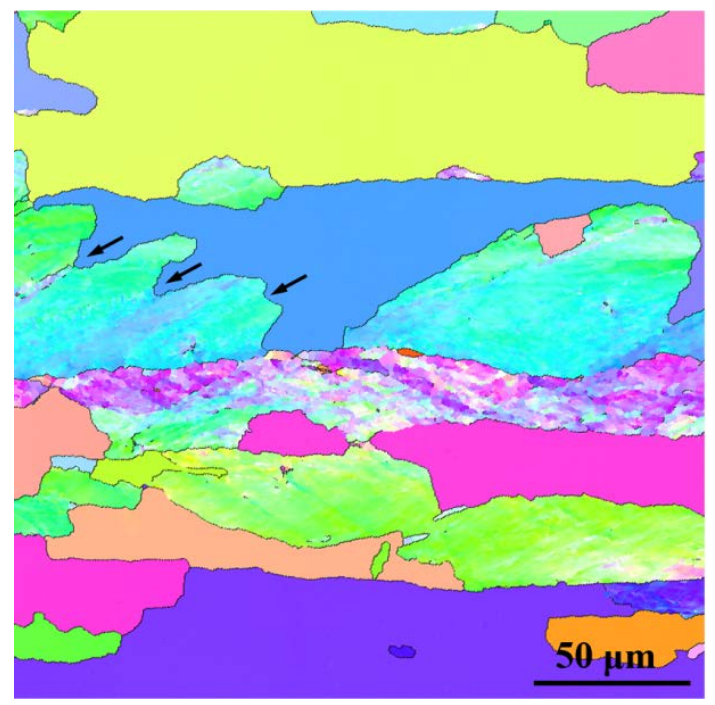

(a)
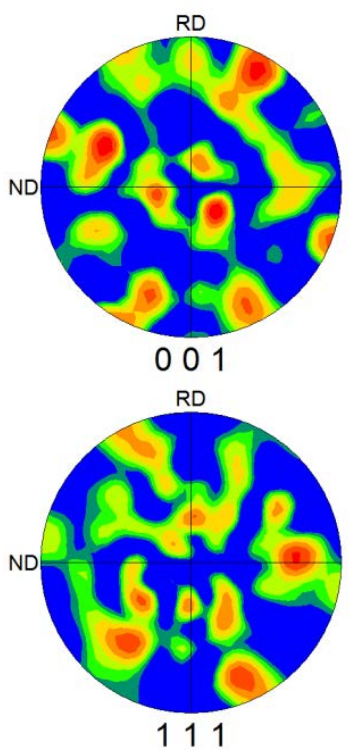

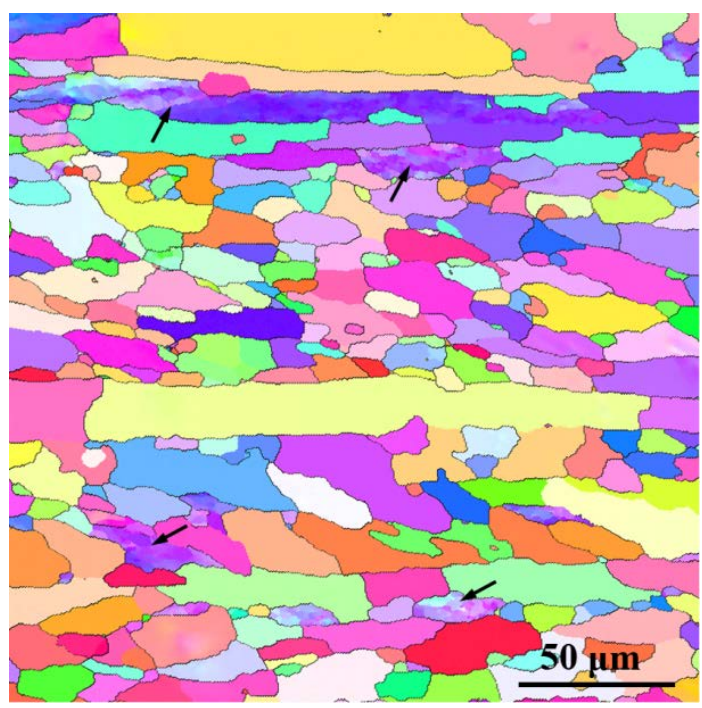

(b)
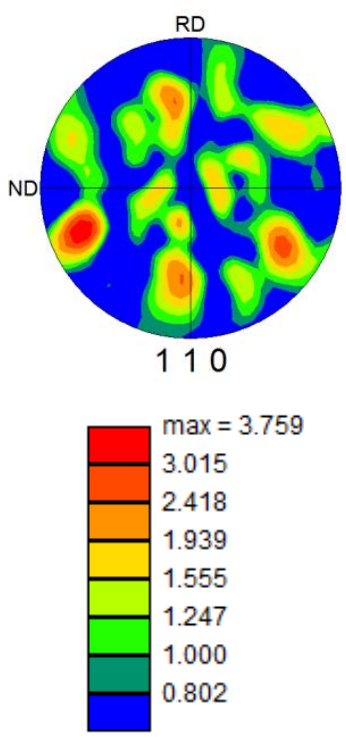

(c)

Figure 19. IPF maps of C36N samples after annealed for $24 \mathrm{~h}$ at (a) $800^{\circ} \mathrm{C}$ and (b) $900^{\circ} \mathrm{C}$. Grain boundaries with the misorientation greater than $15^{\circ}$ are marked by black lines. The (001), (110), and (111) pole figures of (b) are shown in (c). 


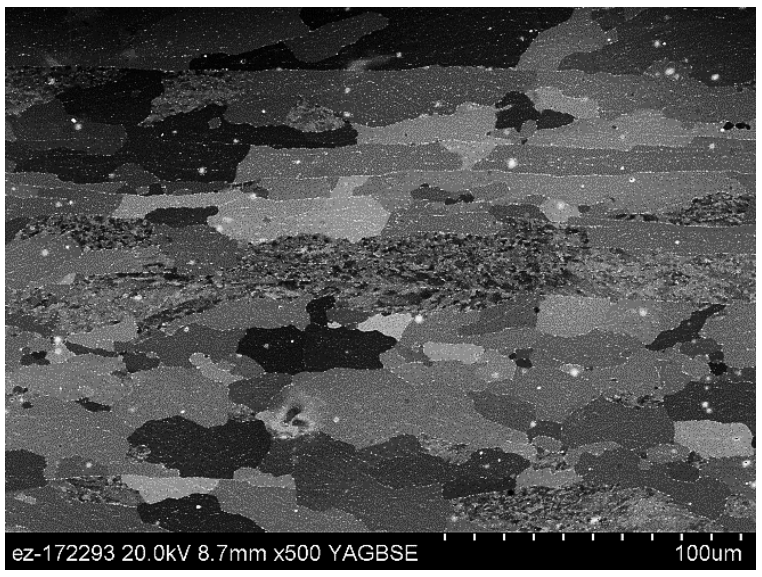

(a)

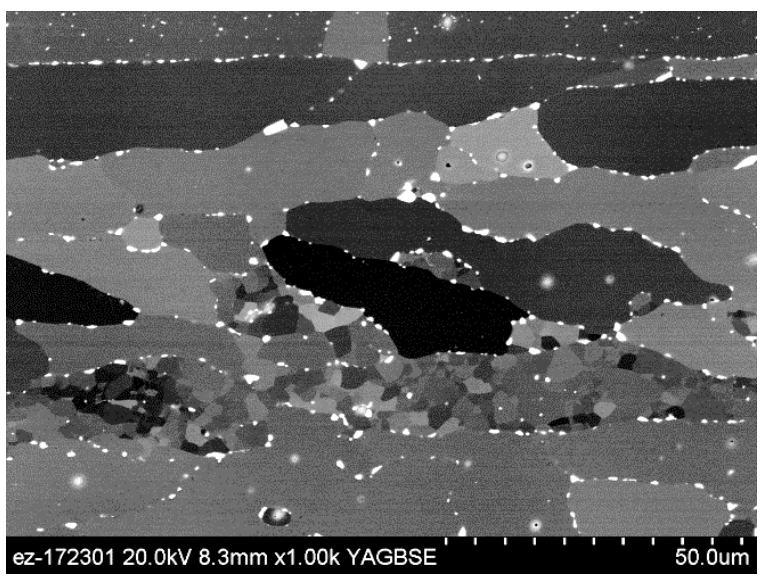

(b)

Figure 20. Backscattered electron images of C36N samples annealed at $900^{\circ} \mathrm{C}$ for (a) $1 \mathrm{~h}$ and (b) $24 \mathrm{~h}$.

\subsubsection{Mechanical properties of deformed and annealed samples}

Figure 21a shows the annealing effects on the Vickers hardness of $\mathrm{C} 36 \mathrm{~N}$ at $600-900^{\circ} \mathrm{C}$. Overall, the hardness decreased as the annealing time increased. There were hardness plateaus at 600,650 , and $700^{\circ} \mathrm{C}$, where the hardness slightly decreased or stayed constant. All other Nb-containing FeCrAl alloys showed similar trends with C36N. Figure 21b compares the annealing effects on C36N, C36N2, C36N3, and $\mathrm{C} 36 \mathrm{M} 2$ at $700^{\circ} \mathrm{C}$. As shown in Figure 21c, the annealing treatment softened as-rolled C36N and increased its deformability.
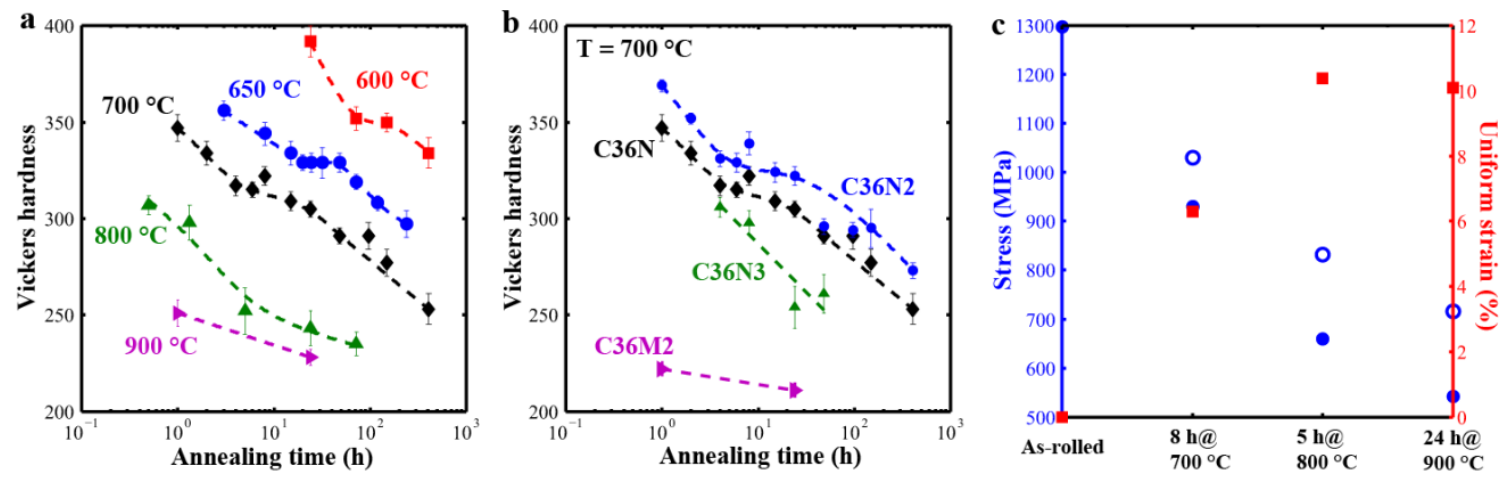

Figure 21. (a) Effect of annealing at $600-900{ }^{\circ} \mathrm{C}$ on the Vickers hardness of C36N samples; (b) Comparison of the annealing effect at $700{ }^{\circ} \mathrm{C}$ on the Vickers hardness of C36N, C36N2, C36N3, and C36M2 samples; (c) Tensile properties of as-rolled and annealed C36N samples. 


\section{ATF FECRAL TUBE PRODUCTION VIA COMMERCIAL MANUFACTURERS}

\subsection{Tube Drawing at Century Tubes, Inc.}

Century Tubes, Inc. (CTI) successfully produced thin-wall FeCrAl alloy tubes of both Gen I and Gen II alloys through cold-drawing and annealing. It was found that the control of grain structure (preventing grain coarsening) would be the key to better tube fabricability, uniform wall thickness, and (potentially) improved mechanical properties of final tube products. CTI produced thin-wall tube products of Gen I B126Y (total 21ft length) and Gen II C06M2 (total 5ft length) alloys in FY2016. Additional tube production of Gen II C36M3 (expected 10ft length) and Gen I B136Y3 (expected 250ft length) is currently in progress, and the expected delivery date is in the middle of June and the end of July, respectively.

In FY2014, CTI successfully produced thin-wall seamless tubes of the Gen I model FeCrAl alloys, Fe13Cr-4.5Al-Y (T35Y2) and Fe-15Cr-4Al-Y (T54Ys) [11]. CTI used tube-drawing processes at room temperature, combined with intermediate annealing. The detailed process parameters were proprietary. Although the first thin-wall tube production was successful, the microstructure consisted of coarse grains ( 100-200 $\mu \mathrm{m}$ in size) which were not suitable in terms of mechanical properties. Tube-burst testing of the sealed tubes was carried out at ORNL. They exhibited relatively poor barreling deformation resistance bursting during the ramp test [12]. Microstructural characterization clearly showed some of the coarse grains with heavily deformed features, resulting in strain concentration which leads to premature failure. This suggests that microstructural control, especially for grain refinement, would play an important role in the properties of tube products.

CTI also produced thin-wall FeCrAl alloy tubes of Gen II modified FeCrAl alloys, Fe-10Cr-6Al-2Mo base (C06M2), as shown in Figure 22. Optimized process parameters for C06M2 successfully controlled the microstructure with fine and uniform grains $(\sim 10-20 \mu \mathrm{m}$ in size). The small grain size was beneficial (and required) for obtaining uniform wall thickness of the tube product. The detailed cross-sectional characterization results are shown in Figure 23, which clearly indicated better concentricity compared to C35M3 tube produced by RAI in FY2015 [12].

Based on these results, close attention will be required during current tube production at CTI to prevent unnecessary grain coarsening during the tube fabrication processes as well as in the final tube products. The recently-procured tubes (C36M3 and B136Y2) will be characterized in a similar way and evaluated for property screening including tensile testing, oxidation testing, and irradiation testing.

\subsection{Tube Drawing at Rhenium Alloys, Inc.}

Rhenium Alloys, Inc, (RAI) has been working with ORNL on FeCrAl tube fabrication using the warmdrawing process. Several trials to process or produce the Gen II FeCrAl alloy tubes, such as C35MN5B (Fe-13Cr-5.2Al-2Mo-1Nb-0.2Si-Y), C35M3 (Fe-13Cr-5.2Al-2Mo-0.2Si-Y), C36M2 (Fe-13Cr-6Al-2Mo0.2Si-Y), and C37M (Fe-13Cr-7Al-2Mo-0.2Si-Y), were conducted. Only C35M3 was successfully tubedrawn to achieve the target outer diameter, but the final wall thickness was not uniform. This was due to unexpected grain coarsening during non-optimized intermediate annealing, as summarized in the previous report [12] or Section 3.2.3. The other tube drawings of C35MN5B, C36M2, and C37M resulted in premature failure early in the warm-drawing [12] reduction process. These failures did provide important data points regarding FeCrAl deformability; specifically on the effect of alloying additions on work hardening, initial microstructure, hardness control prior to the tube drawing, the upper limit of the area reduction without intermediate annealing, the effect of intermediate annealing conditions, and so on. 
(a) as-received C06M2 tube

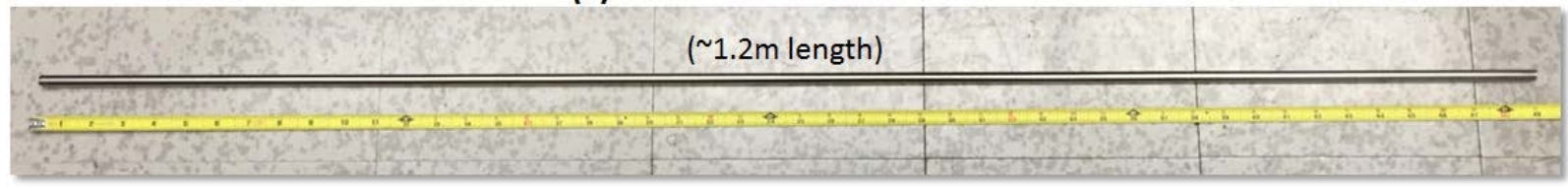

(b) cross section

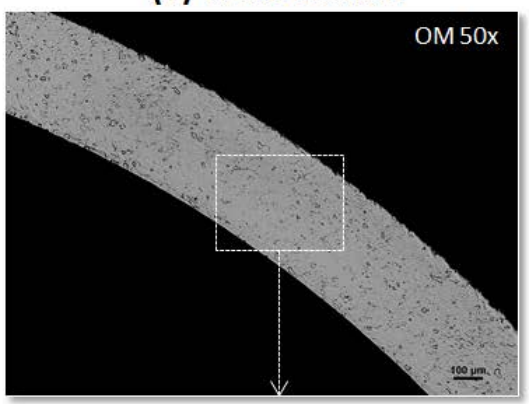

(c) longitudinal section
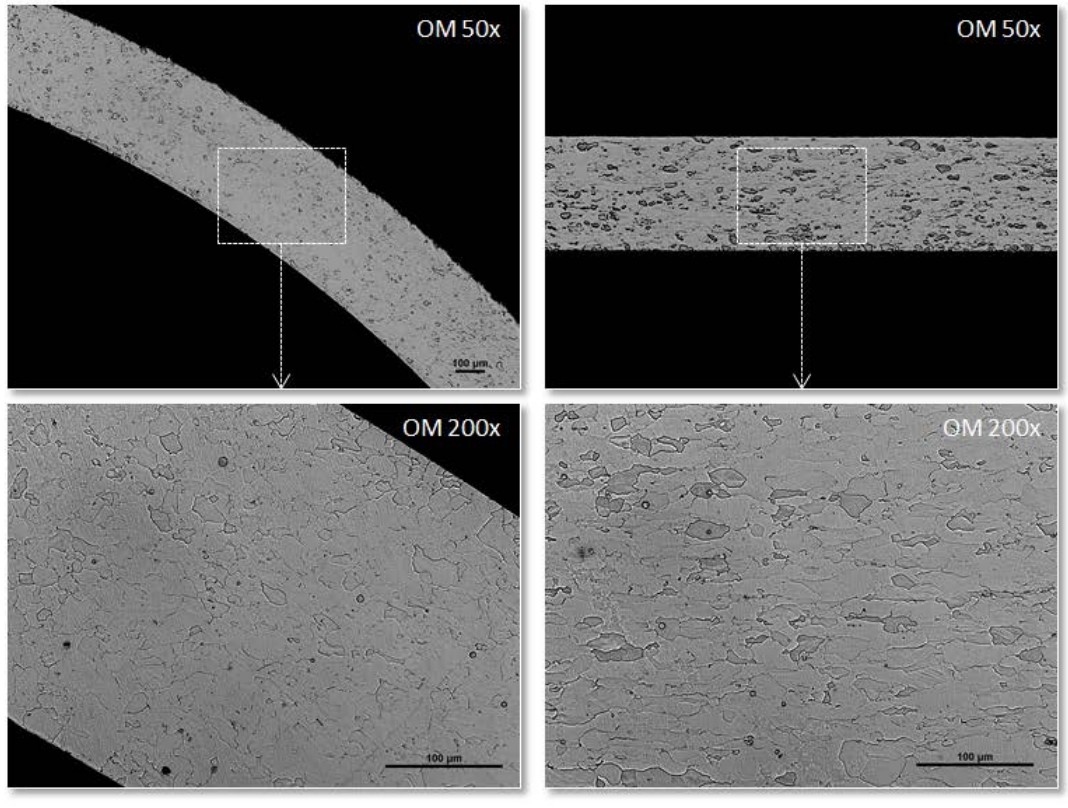

Figure 22. As-received C06M2 thin wall tube produced by CTI; a picture of whole tube (a), and optical micrographs of cross section (b) and longitudinal section (c).

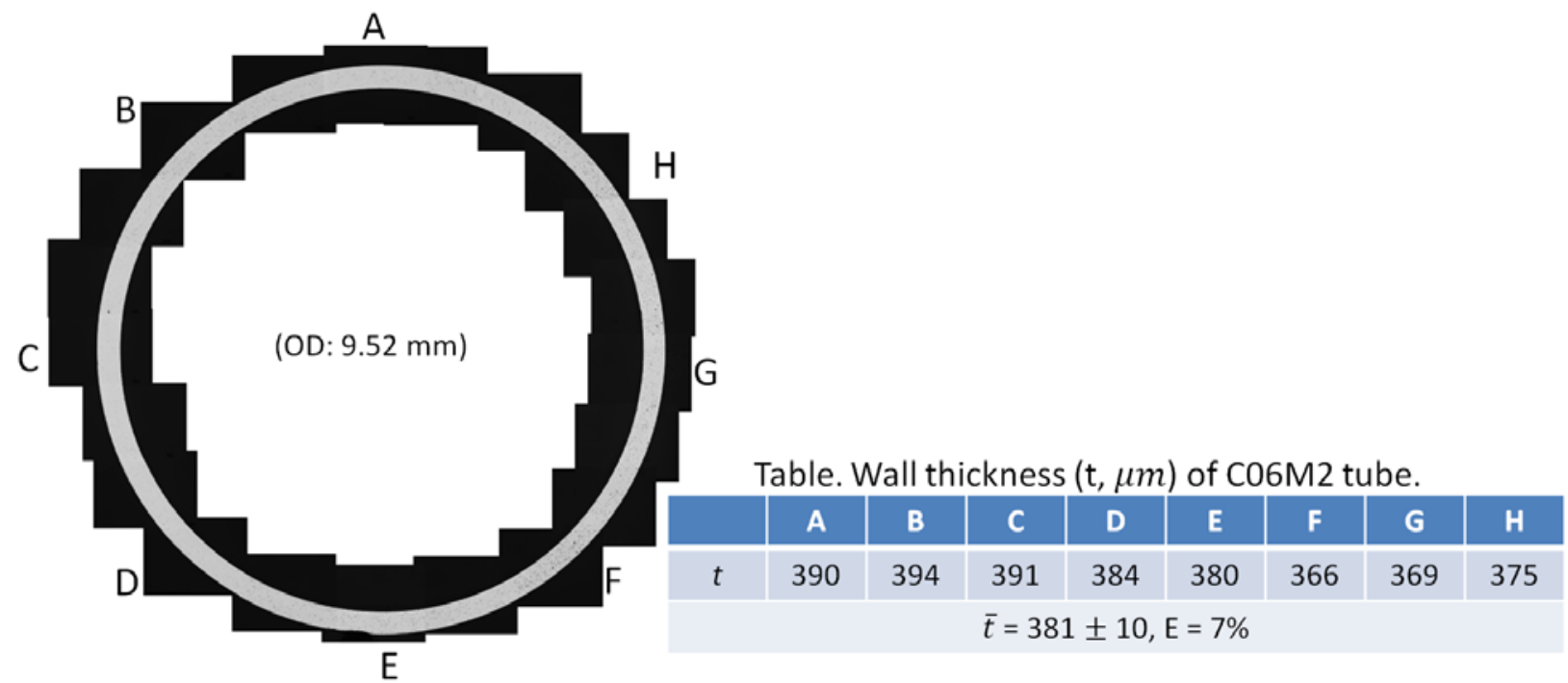

Figure 23. Optical micrograph montage of cross-sectional view of as-received C06M2 tube, together with a list of wall thickness at various locations. 
The large-quantity tube production of C35M4 alloy is currently in progress at RAI with the aim to produce a total of $250 \mathrm{ft}$ length in tubes. The suggested process parameters based on the effort in sections 3.1 and 3.2 has been shared with RAI, and is utilized in the current process. RAI has been performing microstructural characterizations and the hardness analyses at each process step (after drawing and annealing) to monitor that there are no strange microstructural features or hardness changes during this process. The expected completion date is in the middle of June. Once the production is completed, the recently-procured tubes (C35M4) are to be characterized in similar way to the previous tubes, and evaluated for property screening including tensile testing, oxidation testing, and irradiation testing.

\subsection{Pilgering at Superior Tube Company, Inc.}

The cold-pilgering process is one of the major industrial tube fabrication processes. It is suitable for continuous tube mass production. It is not easily adaptable for lab-scale tube production evaluation using the existing equipment at commercial manufacturers as it requires stopping the current production process. However, it is a very attractive process for $\mathrm{FeCrAl}$ tube production since the deformation sequence during reduction is almost identical to the conventional rolling process, indicating that much less force is required during processing (i.e. eliminating the frictional forces inherent in the tube-drawing process). In addition, the pilgering process is basically a compressive process such that the materials are less likely to tear compared to the tensile processes in tube-drawing. Therefore, it is worthwhile to attempt the tube production through the pilgering process to evaluate how the process would be beneficial for FeCrAl tube production (e.g. widen the process window to make potential mass tube production easier in the future).

Superior Tube Company, Inc. (STC) has agreed to support the lab-scale tube production of FeCrAl alloys. The extruded and annealed bars of C06M2 and C36M3 alloys were provided. These were identical to the materials processed/being processed at CTI. Therefore, direct comparison of tube production between the drawing and the pilgering processes is expected. The bar materials were gun-drilled at the end of May. The detailed discussion of process parameters has been initiated between STC and ORNL. The delivery date has not been scheduled yet, but is expected in July/August in 2016. 


\section{SUMMARY}

Two major concerns in ATF FeCrAl alloy tube production have been discussed in this report; (1) optimization of microstructural control of ATF FeCrAl alloys during the tube drawing process, and (2) provision of an update on the progress of ATF FeCrAl tube production via commercial manufacturers.

Experimental efforts have been made to optimize the process parameters balancing tube fabricability, especially for tube drawing processes, and microstructure control of the final tube products. Lab-scale sheet materials of Gen II FeCrAl alloys (Mo-containing and Nb-containing FeCrAl alloys) were used in the study, combined with a stepwise warm-rolling process and intermediate annealing, simulating the tube drawing process at a commercial tube manufacturer. The intermediate annealing at $650^{\circ} \mathrm{C}$ for $1 \mathrm{~h}$ was recommended for tube-drawing processes of Mo-containing FeCrAl alloys (C35M4, Fe-13Cr-5.2Al-2Mo base) because it successfully softened by recovering the work hardening introduced through the rolling step, without any grain coarsening occurring from recrystallization. The final tube product is expected to have a stabilized deformed microstructure providing improved tensile properties with sufficient ductility. In contrast, the intermediate annealing at $871^{\circ} \mathrm{C}$ for $30 \mathrm{~min}$ resulted in grain coarsening due to recrystallization during processing, leading to potentially non-uniform wall thickness observed in C35M2 in FY2015 [12]. Optimization efforts on Nb-containing FeCrAl alloys focused on the effect of alloying additions and annealing conditions on the stability of the deformed microstructure. Relationships between the second-phase precipitates $\left(\mathrm{Fe}_{2} \mathrm{Nb}\right.$-Laves phase) and microstructural stability was discussed.

FeCrAl tube production through commercial tube manufacturers is currently in progress. Three different manufacturers, Century Tubes, Inc. (CTI), Rhenium Alloys, Inc. (RAI), and Superior Tube Company, Inc. (STC) are involved, each having a capability of cold-drawing, warm-drawing, and HPTR cold-pilgering, respectively. CTI successfully manufactured two FeCrAl alloy tubes, Gen II C06M2 (Fe-10Cr-6Al-2Mo base) and Gen I B126Y (Fe-12Cr-6Al base) alloys. Microstructural characterization revealed that C06M2 consisting of a refined grain structure with $10-20 \mu \mathrm{m}$ grain size, contributed to the successful production of a thin-wall tube with uniform wall thickness. CTI and RAI are currently working on the large-quantity tube production (expected 250ft length) of Gen I model FeCrAl alloy (B136Y3, at CTI) and Gen II (C35M4, at RAI), with the process parameters obtained from the experimental efforts. The expected delivery dates are the end of July, 2016, and the middle of June, 2016, respectively. For STC, this will be the first attempt to apply cold-pilgering to the FeCrAl alloys. Communication has been initiated and the materials have been machined for the cold-pilgering process.

\section{REFERENCES}

[1] Powers, D.; Meyer, R. Cladding swelling and rupture models for LOCA analysis, NUREG-0630; U. S. Nuclear Regulatory Commission: 1980.

[2] B. A. Pint, K. A. Unocic and K. A. Terrani, Materials at High Temperature, 32 (2015) 28-35.

[3] M. Moalem, D.R. Olander, Journal of Nuclear Materials 182 (1991) 170.

[4] K. Suzuki, S. Jitsukawa, N. Okubo, F. Takada, J.Nucl.Eng. and Design 240 (2010) 1290-1305.

[5] M. Steinbrück, M. Große, L. Sepold, J. Stuckert, Nuclear Engineering and Design 240 (7) (2010) 1714-1727.

[6] Y. Yamamoto, B.A. Pint, K. Terrani, K.G. Field, L.L. Snead, “Letter report documenting identifying billets and alloys fabricated for distribution to program” M3FT-13OR0202291, ORNL/LTR2013/322, Oak Ridge National Laboratory (2013). 
[7] P. Grobner, Metallurgical and Materials Transactions B, 4 (1973) 251-260.

[8] K.G. Field, X. Hu, K.C. Littrell, Y. Yamamoto, L.L. Snead, "Radiation Tolerance of NeutronIrradiated Model Fe-Cr-Al Alloys,” Journal of Nuclear Materials, 465 (2015) 746-755.

[9] K.G. Field, M.N. Gussev, Y. Yamamoto, L.L. Snead, "Deformation behavior of laser welds in high temperature oxidation resistant Fe-Cr-Al alloys for fuel cladding applications,” Journal of Nuclear Materials, 454 (2014) 352-358.

[10] B. A. Pint, S. Dryepondt, K. A. Unocic, and D. T. Hoelzer, JOM, 66 (2014) 2458-2466

[11] Y. Yamamoto, Y. Yang, K.G. Field, K. Terrani, B.A. Pint, and L.L. Snead, “Letter Report Documenting Progress of Second Generation ATF FeCrAl Alloy Fabrication, FY14 FCRD milestone report,” M3FT-14OR0202232, ORNL/LTR-2014/219, Oak Ridge National Laboratory (2014).

[12] Y. Yamamoto, M.N. Gussev, B.K. Kim, T.S. Byun, "Optimized properties on base metal and thinwalled tube of Generation II ATF FeCrAl”, M2FT-15OR0202291, ORNL/TM-2015/414 (2015).

[13] B.A. Pint, K.A. Unocic, K.A. Terrani, "Steam Oxidation of FeCrAl and $\mathrm{SiC}$ in the SATS", M3FT15OR0202342, ORNL/LTR-2015/417 (2015).

[14] K.A. Terrani, S.J. Zinkle, L.L. Snead, “Advanced Oxidation-resistant Iron-based Alloys for LWR Fuel Cladding,” Journal of Nuclear Materials, 448 (2014) 420-435.

[15] H. Qu, Y. Lang, C. Yao, H. Chen, C. Yang, Materials Science and Engineering: A 562 (2013) 9-16.

[16] "Shanghai EverSkill M\&E Co., Ltd”: http://www.esmeind.com/Pro-Tube.html\#

[17] "Cold Pilger Rolling: Part One" in the website of Total Materia, Apr. 2013: http://www.totalmateria.com/page.aspx?ID $=$ CheckArticle\&site $=k t s \& N M=396$

[18] Albert Nerino, Mark Deaver, Chris Nagele, John Reinhart , "HPTR's past, present, and future Part I”, TPJ - THE TUBE \& PIPE JOURNAL® , Jun. 2011: http://www.thefabricator.com/article/tubepipeproduction/hptras-past-present-and-future-a-part-i 